\title{
Coupled thermo-electro-mechanical models for thermal ablation of biological tissues and heat relaxation time effects
}

\author{
Sundeep Singh ${ }^{1 *}$ and Roderick Melnik ${ }^{1,2}$ \\ ${ }^{1}$ MS2Discovery Interdisciplinary Research Institute, Wilfrid Laurier University, \\ 75 University Avenue West, Waterloo, Ontario, N2L 3C5, Canada \\ ${ }^{2}$ BCAM - Basque Center for Applied Mathematics, \\ Alameda de Mazarredo 14, E-48009 Bilbao, Spain
}

The reference to the final published version of this paper is: Sundeep Singh \& Roderick Melnik, "Coupled thermo-electro-mechanical models for thermal ablation of biological tissues and heat relaxation time effects." Physics in Medicine \& Biology, 64(24), 245008, (2019). 


\begin{abstract}
Thermal ablation is a widely applied electrosurgical process in medical treatment of soft biological tissues. Numerical modeling and simulations play an important role in prediction of temperature distribution and damage volume during the treatment planning stage of associated therapies. In this contribution we report a coupled thermo-electro-mechanical model, accounting for heat relaxation time, for more accurate and precise prediction of the temperature distribution, tissue deformation and damage volume during the thermal ablation of biological tissues. Finite element solutions are obtained for most widely used percutaneous thermal ablative techniques, viz., radiofrequency ablation (RFA) and microwave ablation (MWA). Importantly, both tissue expansion and shrinkage have been considered for modeling the tissue deformation in the coupled model of high temperature thermal ablation. The coupled model takes into account the non-Fourier effects, considering both single-phaselag (SPL) and dual-phase-lag (DPL) models of bio-heat transfer. The temperature-dependent electrical and thermal parameters, damage-dependent blood perfusion rate and phase change effect accounting for tissue vaporization have been accounted for obtaining more clinically relevant model. The proposed model predictions are found to be in good agreement against the temperature distribution and damage volume reported by previous experimental studies. The numerical simulation results revealed that the non-Fourier effects cause a decrease in the predicted temperature distribution, tissue deformation and damage volume during the high temperature thermal ablative procedures. Furthermore, the effects of different magnitudes of phase lags of the heat flux and temperature gradient on the predicted treatment outcomes of the considered thermal ablative modalities are also quantified and discussed in detail.
\end{abstract}

Keywords: Thermal Ablation, Thermo-electro-mechanical Model, Non-Fourier Bio-heat Transfer, Microwave Ablation, Radiofrequency Ablation, Heat Relaxation Time, Tissue Expansion and Shrinkage, Computational Modeling. 


\section{Introduction}

Since the advent of modern imaging, thermal ablation has emerged as a prominent modality for treating a wide range of primary and secondary solid neoplasms, virtually in all major organs [1]. During the thermal ablation procedure, fatally high or low temperature is applied intentionally over the course of several minutes to cause the irreversible cellular injury. The most common methods of thermal ablation are: radiofrequency ablation (RFA), microwave ablation (MWA), laser ablation, high-intensity focused ultrasound (HIFU), and cryoablation $[1,2]$, with RFA and MWA being the clinically dominant modalities. These minimallyinvasive thermal ablative modalities are potentially cheaper as compared to conventional therapies and result in notable decrease in morbidity, increased preservation of surrounding tissue, fewer complications, quicker recovery and a shorter hospital stay. However, there are also certain associated disadvantages which include, e.g., incomplete ablation, disease recurrence and inferior outcomes [2, 3]. Further, the efficacy of such techniques is significantly dependent upon the type of modality in consideration and the target disease to be treated.

Numerical modeling and simulations of thermal ablation plays a vital role in the successful development, optimization and implementation of these systems in clinical practices. Numerical simulations serve as a powerful tool to predict such important characteristics as the temperature distribution and coagulation volume during thermal ablation. They give a quick, convenient and inexpensive a priori information during the treatment planning stage of the modality to the clinical practitioners. Several numerical studies have been reported in the past on the modeling of the thermal ablative modalities utilizing thermo-electric analysis for evaluating their efficacy among different target tissues [4-23]. However, in most of the analyses the induced thermo-elastic deformations due to nonuniform temperature distribution within the biological tissues have been neglected or underestimated. Importantly, the rising temperature during thermal ablative modalities could significantly contribute to shape or size variations of the biological tissue due to the induced thermal strain. Both contractions and expansions have been noticed and reported in the literature in the previous clinical studies of thermal ablation [24-36]. At the same time, very few numerical studies are available in literature that incorporate systematically the thermoelastic wave equation for capturing mechanical deformations induced by thermal expansion during thermal ablative procedures [37-43]. Moreover, tissue contraction induced by protein denaturation at elevated temperatures during thermal ablation procedures have been clearly missing in such numerical studies. More recently, few numerical studies have also been reported to predict the tissue shrinkage during thermal ablation, but incorporation of such 
predictive models in the actual numerical simulations of the ablative procedures is still missing [34-35]. Importantly, ignoring the impact of tissue contraction results in a significant underestimation of the predicted ablation volume as compared to the actual dimensions of the destroyed tissue as highlighted in previous studies (see e.g. [31-33, 36, 44-45]). A finite difference method based study reported by Park et al. [46] has proposed a mathematical framework to incorporate the tissue contraction model during typical ablation procedures by incorporating the protein denaturation shrinkage term in the thermo-elastic deformation model. Importantly, in this study the bio-heat transfer equation was not solved directly, rather a simple pre-described ablation temperature based on a Gaussian function was used to represent the temperature distribution during thermal ablation. Although, the focus of the study was to report the mathematical model to quantify the tissue contraction during thermal ablation, the effects of thermo-electric coupling were clearly neglected.

Further, the classical Fourier's law based Pennes bio-heat transfer equation is most commonly used for computing the temperature field in the thermal therapies, due to its relative ease of implementation [47]. The major criticism of the Pennes bio-heat transfer equation is that it is unable to take into account the thermal effect of large blood vessels within the biological tissue and presumes that heat transfer occurs at infinite speed. However, heat transfer in non-homogeneous media like biological tissues, containing microscopic inhomogeneities such as macromolecules and cell organelles organized in cellular structures, always occurs at a finite speed with some thermal delay, as has been observed by experimental studies reported in literature [48-54]. Moreover, thermo-physical and electrical parameters (viz., thermal conductivity, diffusivity, specific heat capacity, electrical conductivity, electrical permittivity and blood perfusion rate) of the biological tissues subjected to thermal ablation are assumed to be constant in most of the computational studies available in literature. However, clinically the behavior of these parameters are generally non-linear and often spatio-temporally temperature dependent. Although, there are a number of studies which have incorporated the (sparse) knowledge on temperature dependence of dielectric and thermal properties within the numerical model (e.g., 44, 55-59).

The aim of the present study is to develop a new improved coupled thermo-electromechanical model for more accurately predicting the performance of thermal ablation procedures. The main focus is given to the most extensively and widely applied percutaneous thermal ablative techniques in clinical practices for disease treatment, viz., RFA and MWA. The comparative studies have been conducted for different cases of Fourier heat transfer (Pennes bio-heat model) and non-Fourier heat transfer models considering time phase lag for both temperature gradient and heat flux, i.e. accounting both single-phase-lag (SPL) and 
dual-phase-lag (DPL) models. To obtain more clinically relevant models, the temperaturedependent electrical and thermal properties, damage-dependent blood perfusion rate and phase change effect accounting for tissue vaporization have been taken into consideration. The developed model will integrate the electromagnetic interaction, heat transfer analysis, thermally induced mechanical deformation (both expansion and contraction) and damage quantification for improving the accuracy of prediction of temperature distribution and damage volume during the treatment planning stage of thermal ablative procedures.

\section{Model, materials, and methods}

This section provides the details of the mathematical and computational framework, computational geometry for main selected cases and thermo-electro-mechanical characteristics.

\subsection{Thermo-electro-mechanical model of thermal ablation}

\subsubsection{Modeling of electromagnetic interaction with the biological tissue}

Ideally, electromagnetic energy is applied to heat the biological tissues during thermal ablation. The propagation and interaction effects of electromagnetic fields are well described by Maxwell's equations that form the basic framework of all the classical electromagnetic field theory. The interaction of the electromagnetic waves with the biological tissues can be characterized by a transverse electric model, related to geometrical symmetries of the thermoelectromagnetic model. The general form of Maxwell's equations for the transverse electric wave mode can be presented by the Helmholtz harmonic wave equation for computing the electromagnetic field within the biological tissue [6] during MWA procedures and is given by:

$$
\nabla \times \mu_{r}^{-1}(\nabla \times \boldsymbol{E})-k_{0}^{2}\left(\varepsilon_{r}-\frac{j \sigma}{\omega \varepsilon_{0}}\right) \boldsymbol{E}=0,
$$

where $\boldsymbol{E}$ is the electric field vector, $\mu_{r}$ is the relative permeability, $\varepsilon_{r}$ is the relative permittivity, $\sigma$ is the electrical conductivity, $\varepsilon_{0}$ is the permittivity of free space, $\omega$ is the angular frequency, $k_{0}$ is the free space wave number and $j=\sqrt{-1}$.

The absorbed electromagnetic energy $\left(Q_{p}\right)$ computed from the electromagnetic field distribution in the tissue is given by

$$
Q_{p}=\frac{1}{2} \sigma|\boldsymbol{E}|^{2} .
$$

Further, in the lower frequency range of $\approx 500 \mathrm{kHz}$, as is being used during RFA, the wave length of the electromagnetic field is several orders of magnitude larger than the size of the 
active electrode. Thus, the biological medium can be considered almost totally resistive and the quasi-static approximation can be used to solve the electromagnetic problem without compromising accuracy [60]. Quasi-static electromagnetic field theory presumes that the extent of variation of electric and magnetic fields is negligible and is very similar in characteristics to the static fields, although the fields vary with time. Thus, a simplified form of Maxwell's equations in quasi-static approximation can be used to evaluate the voltage distribution during RFA procedures by solving the generalized Laplace equation:

$$
\nabla \cdot \sigma \nabla V=0
$$

where $V$ is the voltage and the electric field intensity $(\boldsymbol{E})$ for the quasi-static approximation of Maxwell's equations is computed from the standard potential field approximation:

$$
\boldsymbol{E}=-\nabla V
$$

\subsubsection{Modeling of bio-heat transfer}

Currently, the analysis of heat conduction within the biological tissues is mostly based on the classical Fourier's law which assumes that heat propagation occurs at infinite speed. It relates to the heat flux $(q)$ in the following way:

$$
q(\vec{r}, t)=-k \nabla T(\vec{r}, t),
$$

where $k$ is the thermal conductivity and $T(\vec{r}, t)$ is the temperature at point $\vec{r}$ at time $t$.

The generalized Fourier conduction based Pennes bio-heat transfer equation [61], modified by enthalpy method [62-63] to take into account of liquid-vapor phase change and to model tissue vaporization within biological tissue, is given by

$$
\frac{\partial(\rho h)}{\partial t}=k \nabla^{2} T-\rho_{b} c_{b} \omega_{b}\left(T-T_{b}\right)+Q_{m}+Q_{p},
$$

where $\rho$ is the tissue density, $h$ is the enthalpy, $k$ is the thermal conductivity, $T$ is the temperature, $\rho_{b}$ and $c_{b}$ are the density and specific heat of blood, respectively, $\omega_{b}$ is the blood perfusion rate, $Q_{m}$ is the metabolic heat generation, $Q_{p}$ is the heat generation due to external heating source, $T_{b}$ is the temperature of blood and $t$ is time. Further, the enthalpy term in Eq. (6) is related to the temperature of biological tissue by:

$$
\frac{\partial(\rho h)}{\partial t}=\frac{\partial T}{\partial t} \cdot\left\{\begin{array}{lc}
\rho_{l} c_{l} & 0 \leq T \leq 99{ }^{\circ} \mathrm{C} \\
H_{f g} C & 99<T \leq 100{ }^{\circ} \mathrm{C} \\
\rho_{g}{ }^{c}{ }_{g} & T>100{ }^{\circ} \mathrm{C}
\end{array}\right\} .
$$

where $\rho_{i}$ and $c_{i}$ are the density and specific heat of tissue before phase-change, i.e., at temperatures below $100{ }^{\circ} \mathrm{C}$ ( $i=l$ refers to liquid tissue phase) and at post-phase-change, i.e., temperature above $100{ }^{\circ} \mathrm{C}$ ( $i=g$ refers to gas tissue phase), respectively, $H_{f g}$ is the latent heat, 
i.e., the product of water latent heat of vaporization and water density at $100{ }^{\circ} \mathrm{C}$, and $C$ is the tissue water content inside the tissue.

Further, it is well-known that the heat always propagates with a finite speed, thus, in order to account for the thermal wave behavior not captured by classical Fourier's law, a modified heat flux model, originated from Cattaneo and Vernotte works [64-65], is used

$$
q\left(\vec{r}, t+\tau_{q}\right)=-k \nabla T(\vec{r}, t),
$$

where $\tau_{q}$ is the thermal relaxation time that represents the time delay between the heat flux vector and the temperature gradient. The first-order Taylor expansion of Eq. (8) gives:

$$
q(\vec{r}, t)+\tau_{q} \frac{\partial q(\vec{r}, t)}{\partial t}=-k \nabla T(\vec{r}, t) .
$$

Substituting Eq. (6) into Eq. (9) and after some mathematical manipulations using Eqs. 5-6, the thermal wave, or single-phase-lag (SPL), bio-heat transfer equation can be obtained as

$$
\tau_{q} \frac{\partial^{2}(\rho h)}{\partial t^{2}}+\frac{\partial(\rho h)}{\partial t}+\tau_{q} \rho_{b} c_{b} \omega_{b} \frac{\partial T}{\partial t}-\tau_{q} \frac{\partial Q_{m}}{\partial t}-\tau_{q} \frac{\partial Q_{p}}{\partial t}=k \nabla^{2} T-\rho_{b} c_{b} \omega_{b}\left(T-T_{b}\right)+Q_{m}+Q_{p}
$$

Next in order, to take into account the effect of micro-structural interactions along with fast transient effects of heat transport, an effect absent in thermal wave single phase lag model, i.e., a phase lag for temperature gradient $\tau_{T}$ is introduced in $\mathrm{Eq}(8)$, and the corresponding equation, known as the dual-phase-lag (DPL) equation [66], is given by

$$
q\left(\vec{r}, t+\tau_{q}\right)=-k \nabla T\left(\vec{r}, t+\tau_{T}\right),
$$

where $\tau_{q}$ is the phase-lag in establishing the heat flux and is introduced to take account fast transient thermal wave effects, while $\tau_{T}$ is the phase-lag in establishing the temperature gradient across the medium that accounts for micro-structural interactions. Importantly, the heat flux precedes the temperature gradient for $\tau_{q}<\tau_{T}$ and the temperature gradient precedes the heat flux for $\tau_{q}>\tau_{T}$. Considering $\tau_{T}=0$, Eq. (11) reduces to the thermal wave model (Eq. (8)), and further reduces to Fourier's heat equation (Eq. (5)) by also setting $\tau_{q}=0$.

Substituting Eq. (6) into Eq. (11) and after some mathematical manipulations using Eqs. 5-6, the dual-phase-lag bio-heat transfer equation can be obtained as

$$
\begin{aligned}
& \tau_{q} \frac{\partial^{2}(\rho h)}{\partial t^{2}}+\frac{\partial(\rho h)}{\partial t}+\tau_{q} \rho_{b} c_{b} \omega_{b} \frac{\partial T}{\partial t}-\tau_{q} \frac{\partial Q_{m}}{\partial t}-\tau_{q} \frac{\partial Q_{p}}{\partial t}-\tau_{T} k \nabla^{2} \frac{\partial T}{\partial t} \\
& =k \nabla^{2} T-\rho_{b} c_{b} \omega_{b}\left(T-T_{b}\right)+Q_{m}+Q_{p} .
\end{aligned}
$$

Importantly, the different values of thermal relaxation times reported from previous experimental studies on biological tissues have been presented in Table 1. As is evident from Table 1, there is a visible variability in the thermal relaxation time of biological tissues, especially with regard to thermal relaxation time associated with SPL model that represents the time delay between the heat flux vector and the temperature gradient. To address this 
variability issue, the present study has considered different values of $\tau_{q}$ (viz., 2, 8, 16 and 20 s). While the value of $\tau_{T}$ has been considered to be $0.045 \mathrm{~s}$, disregarding the cases where the restriction for the values of two time lags $\tau_{q} \geq \tau_{T}$ is not obeyed, as for such cases Eq. (11) would violate the causality principle, as highlighted in [67].

\subsubsection{Modeling of mechanical deformation of biological tissues}

The physical problem of thermo-elastic deformation caused by the elevated temperature during thermal ablation procedures of the biological soft tissues has been described mathematically using the modified stress-strain equation, including the effects of thermal expansion and protein denaturation (Eq. 13) and the thermo-elastic wave equation (Eq. 16) [41-42, 46, 68], as follows:

$$
\bar{\sigma}_{i j}=2 \mu \varepsilon_{i j}+\lambda \varepsilon_{k k} \delta_{i j}-(3 \lambda+2 \mu)\left(\varepsilon^{t h}-\beta \xi\right) \delta_{i j},
$$

where $\bar{\sigma}$ is the stress tensor and $\varepsilon=\left[\left(\nabla \mathrm{u}^{\mathrm{T}}+\nabla \mathrm{u}\right) / 2\right]$ is the strain tensor $(i, j=1,2,3$ are the tensor indices representing geometry's coordinate axes and $\mathrm{kk}$ subindices indicate the trace of the strain tensor), $u$ is mechanical displacement vector, $\mu=[E / 2(1+v)]$ and $\lambda=[v E /(1+v)(1-2 v)]$ are the Lame's constants, $E$ is the Young's modulus, $v$ is the Poisson's ratio, $\varepsilon^{\text {th }}$ is the thermal strain given by Eq. (15), $\beta$ is the coefficient of volumetric protein denaturation shrinkage assumed to be equal to three [46], $\xi$ is the relative shrinkage due to protein denaturation given by Eq. (20) and $\delta$ is the Kronecker delta function given by

$$
\delta_{i j}=\left\{\begin{array}{ll}
1 & \text { for } i=j \\
0 & \text { for } i \neq j
\end{array} .\right.
$$

The thermal strain $\left(\varepsilon^{\text {th }}\right)$ is computed as follows:

$$
\varepsilon^{\text {th }}=\int_{T_{r e f}}^{T} \alpha d T,
$$

where $\alpha$ is the thermal expansion coefficient, $T$ is the temperature computed from bio-heat transfer model and $T_{r e f}=37^{\circ} \mathrm{C}$ is the reference temperature. Importantly, $\varepsilon^{\text {th }}$ and $\beta \xi$ terms in Eq. (13) represent the tissue expansion and shrinkage, respectively, during thermal ablative procedures.

The general form of the thermo-elastic wave equation for an isotropic linear elastic solid can be expressed as:

$$
\rho \frac{\partial^{2} u}{\partial t^{2}}=\nabla \cdot \bar{\sigma}_{i j}+F_{i}
$$

where $\rho$ is the density, $u$ is the mechanical displacement vector, $t$ is the time, $\bar{\sigma}_{i j}$ is the stress tensor component defined in Eq. (13) and $F$ (with $i=1,2,3$ representing the geometry's coordinate axes) is the force density vector that has been assumed to be zero. Eqs. 13-16 
describe the thermo-mechanical behavior of the biological tissue subjected to non-uniform heating during thermal ablation.

\subsubsection{Modeling of thermal damage}

The three-state cell death model [69] has been used to quantify the protein denaturation within the biological tissue subjected to thermal ablative procedures. This model assumes that there are three states (viz., native $(N)$, unfolded $(U)$ and denatured $(D)$ ), and the cells in unfolded state have the potential to recover and return in the native (or alive) state. The reaction equation grouping all the different intermediates states into one overall state is given by:

$$
N \underset{k_{3}}{\stackrel{k_{1}}{\rightleftarrows}} U \stackrel{k_{2}}{\rightarrow} D
$$

where $N, U$ and $D$ are the proportion of cells that are in native (alive), unfolded (vulnerable) and denatured (dead) states, respectively, and $k_{i}$ 's are the reaction rates that describe the forward or backward rates of change in cell states and are assumed to be governed by Arrhenius equation given by:

$$
k_{i}(T)=A_{i} e^{\frac{-\Delta E_{i}}{R T}}
$$

where $A_{i}$ and $\Delta E_{i}$ are the frequency factor and the activation energy, respectively, associated with different reaction rates $\left(k_{i}:=k_{1}, k_{2}, k_{3}\right), R$ is the universal gas constant and $T$ is the temperature computed from bio-heat transfer model. The kinetic parameters $(A$ and $\Delta E)$ account for the morphological changes in the tissue related to thermal degradation of proteins. With the constraint that the sum of all the three states is equal to one (i.e., $N+U+D=1$ ), the three-state death model can be mathematically described by following system of equations [45]:

$$
\frac{d N}{d t}=-k_{1} N+k_{3} U ; \quad \frac{d U}{d t}=k_{1} N-k_{3} U-k_{2} U ; \quad \frac{d D}{d t}=k_{2} U .
$$

Furthermore, assuming that all the protein is in the native (alive) state initially, the relative shrinkage $(\xi)$ can be expressed as [45-46]

$$
\xi=1-N-U \frac{L_{U}}{L_{N}}-D \frac{L_{D}}{L_{N}},
$$

where $L_{U}, L_{D}, L_{N}$ represents the length of proteins for native, unfolded and denatured states, respectively.

The coagulation volume $(\dot{V})$ induced during the thermal ablation has been defined using the tissue viability parameter $G=N($ or $1-U-D)$, that represents the proportion of the 
tissues that are not dead. The present study considers that the tissue is completely destroyed when the viability is less than the threshold value of 0.8 [69-70]. Thus, the coagulation (or damage) volume is computed as the volume integral of the model having $G<0.8$, and is computed from

$$
\dot{V}=\iiint_{G} d V\left(\mathrm{~mm}^{3}\right) \quad(\text { where } G<0.8)
$$

\subsubsection{Modeling of temperature-dependent and damage-dependent bio-physical parameters}

Since, RFA and MWA procedures are performed at different frequencies of $500 \mathrm{kHz}$ and $2.45 \mathrm{GHz}$, respectively, the electrical parameter's value and variation is different in both scenarios. For the MWA procedure, the relative permittivity and electrical conductivity of the biological tissue during MWA has been modeled as a temperature-dependent parameter utilizing sigmoidal functions adopted from the previous studies [44, 71-72] and are given by Eqs. 22 and 23, respectively, as:

$$
\begin{aligned}
& \varepsilon_{r}(T)=44.3\left(1-\frac{1}{1+\exp (6.286-0.0765 T)}\right)+1, \\
& \sigma(T)=1.8\left(1-\frac{1}{1+\exp (5.951-0.0764 T)}\right)
\end{aligned}
$$

where $T$ is the temperature computed from the bio-heat transfer model.

For RFA, the temperature-dependent electrical conductivity of the biological tissue is given by [16]

$$
\sigma(T)=\left\{\begin{array}{ll}
\sigma_{0} \exp ^{0.015\left(T-T_{\text {ref }}\right)} & \text { for } T \leq 99{ }^{\circ} C \\
2.5345 \sigma_{0} & \text { for } 99<T \leq 100{ }^{0} C \\
2.5345 \sigma_{0}-0.50183 \sigma_{0}\left(T-100{ }^{\circ} C\right) & \text { for } 100<T \leq 105{ }^{\circ} C \\
0.025345 \sigma_{0} & \text { for } T>105{ }^{\circ} C
\end{array}\right\},
$$

where $\sigma_{0}=0.2(\mathrm{~S} / \mathrm{m})[12]$ is the electrical conductivity of the tissue at the baseline temperature of $T_{r e f}\left(=37{ }^{\circ} \mathrm{C}\right)$ and, as before, $T$ is the temperature computed from the bio-heat transfer model.

The temperature-dependent thermal conductivity of the tissue considered in the present study during thermal ablation is given by [16]

$$
k(T)=\left\{\begin{array}{ll}
k_{0}+0.0012\left(T-T_{r e f}\right) & \text { for } T \leq 100{ }^{\circ} C \\
k_{0}+0.0012\left(100{ }^{\circ} C-T_{r e f}\right) & \text { for } T>100{ }^{\circ} C
\end{array}\right\},
$$

where $k_{0}=0.502(\mathrm{~W} / \mathrm{m} / \mathrm{K})[12]$ is the thermal conductivity of the tissue at the same measurement points for $T_{r e f}$ and $T$ as in Eq. (24). 
A thermal damage-dependent piecewise model of blood perfusion rate has been used in the present study, whereby complete cessation of the blood perfusion rate is assumed to occur at the threshold of $G<0.8$ within the tissue [70] and is given by

$$
\omega_{b}(G)=\left\{\begin{array}{ll}
\omega_{b} & \text { for } G \geq 0.8 \\
0 & \text { for } G<0.8
\end{array}\right\},
$$

where $\omega_{\mathrm{b}}=0.016 \mathrm{~s}^{-1}[12]$ is the baseline blood perfusion rate of the tissue.

\subsection{Numerical setup}

Figures 1(a) and 1(b) show the two-dimensional axisymmetric computational domains considered in the present study for the MWA and RFA procedures, respectively. The computational domain of MWA model (as shown in Fig. 1(a)) has been motivated by the previous studies [37-38]. A single-slot MW antenna comprises of inner conductor $(\phi=0.27$ $\mathrm{mm})$, dielectric $(\phi=0.67 \mathrm{~mm})$ and outer conductor $(\phi=0.92 \mathrm{~mm})$ having a $1 \mathrm{~mm}$ wide ringshaped slot. It has been enclosed in a polytetrafluoroethylene (PTFE) catheter $(\phi=1.79 \mathrm{~mm})$ for hygienic and guidance purpose [37-38]. A continuous MWA procedure has been performed with the input MW power of $10-60 \mathrm{~W}$ for a duration of 10 minutes at the microwave antenna frequency of $2.45 \mathrm{GHz}[38,44]$. The outer surface of the computational domain for the MWA model has been subjected to scattering boundary conditions, i.e., the electromagnetic wave can pass through the boundary without reflection. The boundaries of the inner and outer conductors of the single-slot MW antenna have been modeled as a perfect electric conductor (PEC) boundary. Thermal insulation boundary condition has been applied at the antenna-tissue interface and outer boundaries of the biological tissue during the MWA procedure and presented in Fig. 1(a) [see e.g., [17, 37-38] for relevant motivation].

The dimensions of the computational domain for the RFA model (as shown in Fig. 1(b)) including the tissue, metallic electrodes and the plastic cover of the RF applicator have been chosen consistently with those available in the literature (e.g., [9]). A constant-power RFA has been performed by applying a constant voltage of $20 \mathrm{~V}$ for a period of 10 minutes [14] at the active tip length of a 22-gauge RF needle electrode. The dispersive ground electrode has been modeled by utilizing a zero voltage electric potential on the outer boundaries of the analyzed domain. It has been assumed that the heat transfer process occurs only in the biological tissue, so a thermal insulation boundary condition has been applied at the outer boundaries of the computational domain during the RFA procedure.

It is noteworthy to mention that both the RF applicator and the MW antenna have been modeled without considering any cooling mechanism in this present study. Further, at each interface of the computational domain for both the MWA and RFA procedures, 
electrical and thermal continuity boundary conditions have been imposed. The initial value of voltage and electric field of the entire computational domain before the onset of MWA and RFA have been considered to be $0 \mathrm{~V} / \mathrm{m}$ and $0 \mathrm{~V}$, respectively. For both MWA and RFA models, the initial temperature has been set to $37{ }^{\circ} \mathrm{C}$, while the initial stress and strain have been set to zero. The material properties considered in the present numerical study are summarized in Table 2. The coupled thermo-electro-mechanical models of thermal ablation, viz., MWA and RFA, have been solved using a finite-element method (FEM) based commercial COMSOL Multiphysics 5.2 software [73] utilizing an adaptive time-stepping scheme. The computational domain has been discretized using heterogeneous triangular mesh elements constructed with a built-in mesh generator. Furthermore, extra mesh refinements at the applicator-tissue interface, where the highest thermal, mechanical and electrical gradients are expected, have been carried out. A mesh convergence analysis has been performed to determine the optimal number of mesh elements that would result in mesh-independent solution. The final mesh comprises of 13653 and 40001 elements for the MWA and RFA models, respectively. All simulations have been conducted on a Dell T7400 workstation with Quad-core $2.0 \mathrm{GHz}$ Intel ${ }^{\circledR} \mathrm{Xeon}^{\circledR}$ processors.

\section{Results}

\subsection{Experimental validation}

In order to verify the accuracy and efficacy of the developed model, the simulated results of the present study have been compared to previous experimental findings, in particular $\mathrm{Wu}$ et al. [74]. A computational model with the same geometrical configuration of tissue $(40 \times 40 \times 50$ $\mathrm{mm}^{3}$ ) (as reported in [74]) has been developed in which a single slot coaxial applicator has been centrally inserted to the depth of $27 \mathrm{~mm}$. The applicator comprises of the four layers, viz., dielectric layer $(0.6 \mathrm{~mm}$ in diameter) sandwiched between inner conductor $(0.2 \mathrm{~mm}$ in diameter) and outer conductor (1 $\mathrm{mm}$ in diameter) which is further coated with the layer of Teflon ( $2 \mathrm{~mm}$ in diameter). A $2 \mathrm{~mm}$ wide ring-shaped slot has been cut off from the outer conductor from which the electromagnetic waves will propagate from the applicator to the tissue. Since the problem presents the axial symmetry both in geometry and physics, a twodimensional axial symmetrical model has been used to reduce the computational cost. A 40 W MWA procedure has been performed at the frequency of $2.45 \mathrm{GHz}$ for $120 \mathrm{~s}$ utilizing the coupled thermo-electro-mechanical model developed in section 2 along with the associated temperature-dependent and damage-dependent properties. The initial temperature of the tissue has been assumed to be $20^{\circ} \mathrm{C}$ and the outside boundary of the tissue has been subjected to natural convection to simulate the heat exchange between the liver and the surrounding 
environment (air) with a convective heat transfer coefficient of $5 \mathrm{~W} / \mathrm{m}^{2} / \mathrm{K}$, analogous to the study of Wu et al. [74].

Figure 2 compares the temperature profiles obtained from the present developed model (that is the coupled thermo-electro-mechanical dual-phase-lag model of MWA with $\tau_{\mathrm{q}}$ $=8 \mathrm{~s}$ and $\tau_{\mathrm{T}}=0.045 \mathrm{~s}$ ) and the study of $\mathrm{Wu}$ et al. [74] at a distance of $2 \mathrm{~mm}$ and $5 \mathrm{~mm}$ radially away from the slot center of the applicator. Apart from the experimental and simulation results of $\mathrm{Wu}$ et al. [74], the present study also considers the simulation results obtained from one of the recently reported study of $\mathrm{Xu}$ et al. [17] that utilized the same experimental geometry and results of [74] for their model validation, but neglecting the tissue deformation and non-Fourier behaviour. As depicted in Fig. 2, the temperature profiles obtained from the present study at the two locations are in much better agreement with the experimental results of Wu et al. [74], as compared to the simulation results of [74] and [17]. Furthermore, the maximal transverse and maximal longitudinal dimensions of coagulation volume obtained from the present study, viz., $14.97 \mathrm{~mm}$ and $26.24 \mathrm{~mm}$ have also been found in reasonable agreement with the experimental results of [74], viz., $14.2 \pm 1.4 \mathrm{~mm}$ and $30.3 \pm 4.5 \mathrm{~mm}$, respectively. The good agreement between the numerical model developed in the present study and the experimental findings of [74] suggests that the present non-Fourier based coupled thermo-electro-mechanical model can more accurately predict the temperature distribution and damage volume during the actual thermal ablative procedures in clinical practices.

\subsection{Effect of thermo-electro-mechanical coupling on MWA}

The comparison of the temperature profiles with respect to time at four positions, viz., 2.5, 5, 7.5 and $10 \mathrm{~mm}$ radially away from the slot center for the developed model of MWA with and without the inclusion of mechanical coupling (including both expansion and shrinkage of tissue) based on MW power of $20 \mathrm{~W}$ and treatment time of 10 min has been presented in Fig. 3. The temperature differences among the two models at the end of 10 min of MWA procedure have been found to be $0.64 \%, 1.29 \%, 1.87 \%$ and $0.99 \%$ for the positions of $2.5,5$, 7.5 and $10 \mathrm{~mm}$, respectively. Although, from the reported results the variation of temperature distribution in the numerical model with and without mechanical coupling seems to be relatively low during $20 \mathrm{~W}$ MWA, it is expected that this variation is going to increase with increase of applied input power.

The variations in radial and total displacements of tissue with time at four positions, viz., 2.5, 5, 7.5 and $10 \mathrm{~mm}$ radially away from the slot center for the coupled thermo-electro- 
mechanical model of MWA have been presented in Fig. 4. It is noteworthy to mention that cylindrical computational domain of the present numerical study has been simplified to twodimensional axisymmetric computational domain in $r$-z plane, which assumes that the tissue properties and thermo-electro-mechanical conditions along the circumferential direction $\phi$ will be constant. Thus, the displacement (computed from Eqs. 13-16) within the tissue subjected to thermal ablation in 2D axisymmetric $r-z$ plane will be induced in radial direction (say $u_{r}$ in $r$-plane) and axial direction (say $u_{z}$ in $z$-plane), and consequently the displacement along $r$-axis will be more pronounced as compared to $z$-axis since the heat is applied in radially outward direction from the electrode/applicator. Furthermore, the total displacement is computed from: $\sqrt{\sum_{i}\left(\operatorname{real}\left(u_{i}\right)\right)^{2}}$, where indices $i$ refers to geometry's coordinate axes. Importantly, the comparison between the temporal displacements of the tissue has also been made for two cases: (a) coupled thermo-electro-mechanical model including both thermal expansion and tissue contraction (or shrinkage), and (b) coupled thermo-electro-mechanical model including only thermal expansion, i.e., neglecting the effect of tissue shrinkage caused by protein denaturation. Figures 4(a)-(b) present the temporal variations in tissue radial and total displacements, respectively, for the case with inclusion of both the thermal expansion and tissue shrinkage. The displacement of tissue due to shrinkage caused by protein denaturation can be clearly observed in Fig. 4(a). As seen in Figs. 4(a)-(b), the displacement of the tissue peaked early and then decayed over heating time of MWA, especially for the positions much closer to the MW antenna, viz., 2.5 and $5 \mathrm{~mm}$. Further, beyond the $5 \mathrm{~mm}$ location there has been a decrease in the displacement profile that can be attributed to the fact that the maximum displacement has occurred at a location close to $5 \mathrm{~mm}$ radially away from the slot center which is subsequently followed by a decay with increasing distance. The radial and total displacements of the tissue for the coupled thermo-electro-mechanical model of MWA including only the thermal expansion term in the mechanical coupling, i.e., neglecting the tissue shrinkage caused by protein denaturation, have been presented in Figs. 4(c)-(d), respectively. It can be again observed from these figures that the displacement of the tissue increases rapidly during initial time, reaches a peak value and then decays gradually toward a steady state over heating time. Further, the displacement profile increases till the location of $7.5 \mathrm{~mm}$ beyond which it decreases, justifying the occurrence of maximal displacement location due to thermal expansion close to the location of $7.5 \mathrm{~mm}$. The temporal variations in volumetric strain (i.e., unit change in the volume of tissue) for the coupled model with and without the inclusion of tissue shrinkage have been presented in Figs. 4(e) and 4(f), respectively. It can be observed from Figs. 4(e)-(f) that the magnitude of volumetric strain is 
highest for the positions near the slot of MW antenna (i.e. at a location $2.5 \mathrm{~mm}$ ) where the absorbed MW power is highest and consequently maximum temperature differences occur for both cases, followed by the positions of $5 \mathrm{~mm}, 7.5 \mathrm{~mm}$ and $10 \mathrm{~mm}$, respectively.

Figure 5 presents the total displacement distribution within the tissue for the coupled thermo-electro-mechanical model including both tissue expansion and shrinkage during MWA at different time steps. As evident from Fig. 5, the magnitude of tissue total displacement increases with increase in heating time with its greatest values occurring proximal to the slot of MW antenna where the highest temperature distribution was found. Figure 6(a) shows the time course of variation of fractions of cells in native $(N)$, unfolded $(U)$ and denatured $(D)$ states among the developed MWA model with and without the inclusion of mechanical coupling at a position of $2.5 \mathrm{~mm}$ radially away from the slot center. It can be observed from Fig. 6(a) that there is a rapid drop in the protein proportion in the native state, simultaneously resulting in the sharp increase in the protein proportion in the unfolded state that further changes into denatured state with passage of time for both the models. Although the trends of variations of protein proportions in two models among different states is same, the model without mechanical coupling is clearly underestimating the propagation of different states during the MWA procedure. The reason for this can be directly linked to the temporal variation of temperature profile presented in Fig. 3. Again, this variation is expected to increase with increase of applied MW power. Further, the comparison of damage volume predicted for the MWA model with and without the inclusion of mechanical coupling has been presented in Fig. 6(b). As depicted in Fig. 6(b), there prevail significant differences in the quantification of the damage volume utilizing different models. Figure 6(c) presents the comparison of specific absorption rate (SAR) distribution among the MWA model with and without mechanical coupling (including both expansion and shrinkage of tissue), specifically along a line parallel to the MW antenna and at a distance of $2.5 \mathrm{~mm}$ radially away from the slot center (i.e., $0.016 \mathrm{~m}$ ) after a heating time of $1 \mathrm{~min}$. As seen in Fig. 6(c), the peak value of SAR curves for both cases occurred along the axis perpendicular to the slot center. Importantly, for both cases the SAR profile exhibits similar trends but with a slightly lower peak value for the model with mechanical coupling.

Figure 7 presents the effect of input MW power, viz., 10, 20, 30, 40, 50 and $60 \mathrm{~W}$, on the temperature distribution (Fig. 7(a)) and the total displacement of tissue (Fig. 7(b)) at the position of $2.5 \mathrm{~mm}$ radially away from the slot center of MWA antenna. As is evident from Figs. 7(a)-(b), the temperature increases as the input MW power increases, since the greater MW power results in greater SAR and subsequently greater heat generation within the 
biological tissue, thereby increasing the total displacement. The increase in input MW power from $10 \mathrm{~W}$ to $60 \mathrm{~W}$ results in the increase of temperature from $67.39{ }^{\circ} \mathrm{C}$ to $108.05{ }^{\circ} \mathrm{C}$ and subsequent increase in the tissue total displacement from $5.63 \mathrm{~mm}$ to $9.24 \mathrm{~mm}$ at the position of $2.5 \mathrm{~mm}$ radially away from the antenna slot after $10 \mathrm{~min}$ of MWA procedure.

\subsection{Effect of thermo-electro-mechanical coupling on RFA}

The effect of coupled thermo-electro-mechanical coupling (including both expansion and shrinkage of tissue) on the tip temperature and damage volume during RFA has been presented in Fig. 8. As depicted in Figs. 8(a)-(b), there is practically negligible effect of inclusion of the mechanical coupling on both the tip temperature and the damage volume in the thermo-electric model of RFA. Importantly, the variation of only $0.02 \%$ and $0.5 \%$ has been found in the tip temperature and the damage volume predicted by the model after 10 min of RFA procedure. The variations in tissue radial and total displacements along the line radially perpendicular from the tip of RF electrode for the coupled thermo-electro-mechanical model of RFA have been presented in Fig. 9 for the RF heating time of $1 \mathrm{~min}, 3 \mathrm{~min}, 5 \mathrm{~min}$ and $10 \mathrm{~min}$. Again, the comparison between the tissue radial and total displacements has been made for two cases: (a) the model including both thermal expansion and tissue shrinkage (Figs. 9(a)-(b)), and (b) the model including only thermal expansion, i.e., neglecting the effect of tissue shrinkage (Figs. 9(c)-(d)). It is clearly observed from Figs. 9(a) and 9(c) that the radial displacement in the model including both the thermal expansion and tissue shrinkage is far more pronounced here as compared to the model with only thermal expansion term. The highest values of tissue total displacement have been found to be $6.51 \mathrm{~mm}$ and $0.016 \mathrm{~mm}$ for the model with and without inclusion of tissue shrinkage term caused by protein denaturation during RF heating, respectively. Further, for all cases presented in Fig. 9, the displacement increases with increase in the heating time during RFA and this increase is much higher close to the RF electrode where high magnitude of temperature prevails.

\subsection{Effect of single-phase-lag (SPL) and dual-phase-lag (DPL) non-Fourier heat transfer models on the coupled thermo-electro-mechanical model of thermal ablation}

The effect of SPL non-Fourier heat transfer on the coupled thermo-electro-mechanical model of MWA has been presented in Fig. 10, considering different values of SPL, i.e. $\tau_{q}$, viz., $0 \mathrm{~s}$ (Fourier model), 2 s, 8 s, $16 \mathrm{~s}$ and $20 \mathrm{~s}$. The comparisons of temperature distribution, as well as of the tissue total displacement, with respect to time for different values of $\tau_{q}$ at a position 
of $2.5 \mathrm{~mm}$ radially away from the slot center with the MW power of $20 \mathrm{~W}$ has been presented in Figs. 10(a) and 10(b), respectively. It is observed from these figures that there prevails a substantial variation in the predicted temperature and tissue total displacement profiles among different cases. The Fourier heat transfer model $\left(\tau_{q}=0\right)$ clearly overestimate the temperature distribution during MWA procedures. The temperature differences compared to the Fourier Pennes bio-heat transfer model (i.e. $\tau_{q}=0 \mathrm{~s}$ ) at the end of $10 \mathrm{~min}$ of MW heating have been found to be $0.49 \%, 2.37 \%, 5.08 \%$ and $6.40 \%$, for $\tau_{q}=2,8,16$ and $20 \mathrm{~s}$, respectively. Further, the introduction of SPL in the coupled thermo-electro-mechanical model of MWA results in a slight delay in the initiation of damage volume that is dependent on the magnitude of $\tau_{q}$, as depicted in Fig. 10(c). This can be attributed to the initial delay in establishing the heat flux when a temperature gradient is suddenly imposed during MW heating, i.e. a finite speed of heat propagation introduced by the SPL non-Fourier model. The damage volumes predicted by the SPL model as compared to the Fourier model $\left(\tau_{q}=0 \mathrm{~s}\right)$ have been found to be $2.21 \%, 8.11 \%, 17.23 \%$ and $17.48 \%$ lower with $\tau_{q}=2,8,16$ and $20 \mathrm{~s}$, respectively.

Figures 11(a)-(c) present the effect of dual-phase-lag (DPL) non-Fourier heat transfer on the temperature distribution, tissue radial and total displacements at different times along the insertion depth of MW antenna at a distance of $2.5 \mathrm{~mm}$ radially away from the slot center. Importantly, the results in Fig. 11 are presented considering SPL $\left(\tau_{q}=8 \mathrm{~s}\right)$ and DPL $\left(\tau_{T}=\right.$ $0.045 \mathrm{~s}$ ), since the experimental validation study (presented in section 3.1) with these parameters gave the best agreement with the experimental findings of [74]. Further, these selected parameters are in agreement with the previously reported experimental study that investigated non-Fourier effects in biological tissues during laser assisted photothermal therapy [54]. As evident from Figs. 11(a)-(c), there prevail significant variations in the predicted temperature, tissue radial and total displacements distribution among the Fourier and non-Fourier DPL model at the $20 \mathrm{~W}$ MW heating of 1, 3 and 10 minutes, respectively. It has been observed from Fig. 11(a) that among Fourier and non-Fourier DPL models, the MW heating process is faster with the Fourier Pennes bio-heat transfer model, which assumes infinite propagation speed of heat transfer. Further, the variation of temperature and displacement profiles among Fourier and DPL model is more pronounced initially. It decays with increasing time, as has been shown in Figs. 11(a)-(c). The comparison of the time course of variation of fractions of cells in native $(N)$, unfolded $(U)$ and denatured $(D)$ states for Fourier and non-Fourier DPL model at a position of $2.5 \mathrm{~mm}$ radially away from the slot center of MW antenna has been presented in Fig. 11(d). As seen in Fig. 11(d), there prevails a significant variation in the protein proportion in different states among Fourier and non- 
Fourier DPL models, with Fourier model overestimating prediction for each of the states. Further, the variation in the damage volume for Fourier $\left(\tau_{q}=0 \mathrm{~s}, \tau_{T}=0 \mathrm{~s}\right)$, SPL $\left(\tau_{q}=8 \mathrm{~s}, \tau_{T}=0\right.$ s) and DPL ( $\left.\tau_{q}=8 \mathrm{~s}, \tau_{T}=0.045 \mathrm{~s}\right)$ models during the MWA procedure has been presented in Fig. 11(e).

The effect of SPL and DPL non-Fourier heat transfer models on the coupled thermoelectro-mechanical model of RFA has been presented in Fig. 12. The temporal variation of damage volume during $10 \mathrm{~min}$ of RFA procedure has been presented in Fig. 12(a) for different values of $\tau_{q}$, viz., 0 (Fourier), 2, 8, 16 and $20 \mathrm{~s}$. The differences in damage volume after $10 \mathrm{~min}$ of RFA procedure for $\tau_{q}=2,8,16$ and $20 \mathrm{~s}$ have been found to be $0.36 \%$, $0.95 \%, 2.79 \%$ and $3.43 \%$, respectively, as compared to damage volume predicted by the Fourier heat transfer model, i.e., $\tau_{q}=0$ s. Further, Fig. 12(b) presents the temporal variation in damage volume among Fourier, SPL and DPL models. It is seen that a negligible variation prevails in the damage volume for different models of heat transfer. The variation of protein proportions among different states, viz., native (N), unfolded (U) and denatured (D), has been presented in Fig. 12(c) for Fourier and DPL models. Again, it has been observed that the discrepancies between the different profiles are not pronounced among the Fourier and DPL models. The variation of the tip temperature and the total displacement profiles in the biological tissue due to thermal strain for Fourier and DPL models during 10 min of RFA procedure has been presented in Fig. 12(d). The differences in the tip temperature and total displacement post 10 min of RFA have been found to be $0.13 \%$ and $0.94 \%$, respectively.

\section{Discussion}

Existing experimental studies available in literature have highlighted that the exposure of biological tissue to elevated temperatures $\left(>50^{\circ} \mathrm{C}\right)$ during thermal ablative procedures can result in varying degree of mechanical deformation (including both expansion and contraction) within the tissue [24-36]. Several computational studies have also been reported to capture such mechanical deformations, but mainly limited to only thermal expansion [3743]. Importantly, ignorance of the impact of tissue contraction/shrinkage during thermal ablative procedures has resulted in significant underestimation of the predicted ablation volume (see, e.g. [31, 36]). In what follows, the present study aims to develop a new improved coupled thermo-electro-mechanical model for more precisely predicting the ablation volume during thermal ablative procedures. The mechanical deformations induced within the tissue due to both thermal expansion and tissue contraction/shrinkage has been considered in this present work. Furthermore, the non-Fourier heat relaxation time effects on 
the predicted outcomes quantified from the developed coupled thermo-electro-mechanical model has also been systematically investigated during both MWA and RFA procedures.

Our study demonstrated that the model without the inclusion of mechanical coupling, when compared to fully coupled thermo-electro-mechanical model, results in underestimation of the temperature prediction during MWA procedure. Such observed trends of temperature distribution agreed with the earlier reported numerical studies, e.g., [37, 44]. Further, it has been observed that the temporal variation of the temperature profile is practically negligible initially up to a period of 1 min of MWA heating and gradually increases with heating time. This can be attributed to the fact that the induced mechanical deformation within the biological tissue is directly dependent on the temperature rise due to heating during thermal ablation. Since initially the temperature rise is smaller, thus consequently the effect of mechanical deformation will be smaller and will subsequently increase with heating time for all positions. Moreover, it has been observed that the computational model of MWA without mechanical coupling results in underestimation of the temperature prediction at the assumed spatial locations as compared to the fully coupled thermo-electro-mechanical model of MWA. Furthermore, the temperature profiles obtained for different MW powers followed a decreasing exponential profile along the radial distance, which is also similar to the trends obtained in previous studies, e.g., [44].

The developed coupled thermo-electro-mechanical model was able to successfully simulate the mechanical deformations (both expansion and shrinkage) during the thermal ablative procedures. It has been observed that the total displacement of the tissue induced during the MWA procedure increases with, (a) increase of the distance from the MW antenna and (b) increasing treatment time. Such findings are concordant with experimental findings of the previously reported study (e.g., [36, 44]). Further, the maximum values of volumetric strain in the coupled thermo-electro-mechanical model with and without the inclusion of tissue shrinkage have been found to be $34 \%$ and $1.4 \%$, respectively, clearly highlighting the importance of tissue shrinkage term in the computational models of MWA. Moreover, one of the key observations from the coupled analysis is that the magnitude of tissue expansion is of the order of $10^{-5} \mathrm{~m}$, much smaller in magnitude compared to the combined expansion and shrinkage of tissue, i.e., order of $10^{-3}$ to $10^{-2} \mathrm{~m}$. Again, such findings are in agreement with the previously reported thermo-elastic deformation model (see, e.g., [46]). The predicted damage volume of the MWA model without the mechanical coupling is $7.29 \%$ less as compared to the model with mechanical coupling after $10 \mathrm{~min}$ of $20 \mathrm{~W} \mathrm{MW}$ heating. Again, this deviation is expected to increase with the increase in the applied MW power. Thus, the 
approach of including the tissue shrinkage caused by the protein denaturation along with the thermal expansion in the coupled thermo-electro-mechanical model of MWA is clearly justified, leading to models with better predictive capabilities and their increased potential in assisting clinical practices.

Our study also demonstrated that the coupling of mechanical model with the thermoelectric model of RFA has resulted in practically negligible influence on the temperature distribution and damage volume predictions. However, the proposed coupled thermo-electromechanical model including both the thermal expansion and tissue shrinkage can result in more accurate prediction of displacements within the biological tissue during the RFA procedures. Such advanced predicting capabilities, providing vital information, could be quite advantageous in the treatment planning stage of the clinical scenarios when the RFA needs to be performed close to the critical structures and vital organs.

Several previous studies have pointed out at the existence of the non-Fourier behaviour in the biological tissues, emphasizing a finite speed of propagation of thermal signals, prevailing to non-homogeneous inner structures of the tissues [47-54]. Henceforth, to investigate this issue in a systematic manner both single-phase-lag (SPL) and dual-phase-lag (DPL) scenarios have been considered while modeling of the bio-heat transfer during thermal ablative procedures. It has been observed that the Fourier model significantly overestimates the predicted damage volume as compared to the SPL and DPL models. The deviations between the predicted damage volume after $10 \mathrm{~min}$ of MW heating has been found to be $8.11 \%$ and $9.59 \%$ for SPL and DPL model, respectively, as compared to the Fourier heat transfer model. Moreover, a negligible deviation has been found in the predicted damage volume for different models of bio-heat transfer during RFA procedures. Thus, among RFA and MWA procedures, the consideration of non-Fourier heat transfer effects becomes more vital in MWA where the high amount of energy is deposited in shorter time spans, resulting in higher temperature distributions within the biological tissues.

One of the limitations of the current model is that it assumed the biological tissue to be a homogenous and isotropic elastic material that has been modeled using linear elastic model. The incorporation of hyper-elastic model is expected to represent the mechanical deformations within the soft biological tissue subjected to elevated temperature in a more accurate way. Further, the incorporation of porous media model is expected to further strengthen the predicted outcomes from the developed model capturing the heat transfer phenomena at microscopic scale. Another limitation is associated with the deficiencies in the considered thermo-electro-mechanical properties of the tissues that have been derived from 
the mean values or estimates available in literature. Improvement in these properties based on advancement in sophisticated characterization techniques is expected to increase the accuracy of predicted outcomes of the proposed model (see, e.g., [75]). In addition, the tumorous tissue is not taken into consideration within the computational domain along with the lack of direct experimental validation of the proposed model. Future studies are warranted to address these limitations and further improve the accuracy of the proposed model. Indeed, more experimental data and comparative studies are required to derive the definitive conclusions from the proposed model. Despite these limitations, our developed coupled thermo-electromechanical model is one of the initial model that integrates the mechanical deformations (both expansion and contraction) induced within the biological tissue into the thermo-electric model of the thermal ablation. The proposed model is expected to reduce the mismatch between treatment outcomes obtained from the experimental and numerical findings. Our model has significant capabilities of more accurately and precisely simulating the induced mechanical deformations within the tissue along with other treatment outcomes, viz., temperature distribution, damage volume, etc. It is expected that the outcomes derived from the proposed model can be readily integrated to the hospital workflow and assist the clinicians in a decision-making process during the treatment planning stage of such therapies. For e.g., allowing clinicians to optimize the thermal dosage required for attaining successful thermal ablation with minimal damage to the healthy tissue and critical structures.

\section{Conclusion}

For the first time a coupled thermo-electro-mechanical model has been developed and applied, taking into account both tissue shrinkage and expansion, along with analyzing systematically non-Fourier effects during the high temperature thermal ablative modalities, viz., MWA and RFA. It has been found that ignoring the mechanical coupling during the modeling of MWA results in a decrease in the prediction of temperature distribution. It has been observed that the magnitude of displacement considering only tissue expansion in the mechanical coupling is much smaller (order of $10^{-5} \mathrm{~m}$ ) as compared to the magnitude of combined expansion and shrinkage of tissue (order of $10^{-3}$ to $10^{-2} \mathrm{~m}$ ) during the MWA. The deviation between the predicted damage volume obtained from the coupled thermo-electromechanical model of MWA considering Fourier bio-heat transfer model and non-Fourier effects has been found to be $9.59 \%$. The obtained results emphasize the critical importance of utilizing the proposed mathematical framework, especially for accurate predictions of the damage volume during MWA procedures. Moreover, it has been found that the effect of non- 
Fourier based coupled thermo-electro-mechanical coupling is less pronounced in RFA as compared to MWA. Notwithstanding, the proposed model is also an advanced step in simulating the tissue deformation caused during RFA procedures due to its more precise predictions of temperature distribution and damage volume. It is expected that the developed coupled thermo-electro-mechanical model with heat relaxation time included will assist the physicians to improve the treatment planning in more patient-specific models by providing more precise predictions of temperature distribution, tissue deformation and damage volumes during high temperature thermal ablative modalities.

\section{Acknowledgements}

Authors are grateful to the NSERC and the CRC Program for their support. RM is also acknowledging support of the BERC 2018-2021 program and Spanish Ministry of Science, Innovation and Universities through the Agencia Estatal de Investigacion (AEI) BCAM Severo Ochoa excellence accreditation SEV-2017-0718.

\section{References}

[1] Chu K F and Dupuy D E 2014 Thermal ablation of tumours: biological mechanisms and advances in therapy Nature Reviews Cancer 14 199-208

[2] Ahmed M, Brace C L, Lee F T and Goldberg S N 2011 Principles of and advances in percutaneous ablation Radiology 258 351-369

[3] Paulet E et al 2008 Factors limiting complete tumor ablation by radiofrequency ablation Cardiovascular and Interventional Radiology 31 107-115

[4] Prakash P 2010 Theoretical modeling for hepatic microwave ablation The Open Biomedical Engineering Journal 427

[5] Brace C 2011 Thermal tumor ablation in clinical use IEEE Pulse 2 28-38

[6] Chiang J, Wang P and Brace C L 2013 Computational modelling of microwave tumour ablations International Journal of Hyperthermia 29 308-317

[7] Trujillo M and Berjano E 2013 Review of the mathematical functions used to model the temperature dependence of electrical and thermal conductivities of biological tissue in radiofrequency ablation International Journal of Hyperthermia 29(6) 590-597

[8] Lopresto V, Pinto R, Farina L and Cavagnaro M 2017 Treatment planning in microwave thermal ablation: clinical gaps and recent research advances International Journal of Hyperthermia 33(1) 83-100

[9] Ewertowska E, Mercadal B, Muñoz V, Ivorra A, Trujillo M and Berjano E 2018 Effect of applied voltage, duration and repetition frequency of RF pulses for pain relief on temperature spikes and electrical field: a computer modelling study International Journal of Hyperthermia 34 112-121

[10] Singh S and Repaka R 2017 Temperature-controlled radiofrequency ablation of different tissues using two-compartment models International Journal of Hyperthermia 33 122-134

[11] Singh S and Repaka R 2017 Effect of different breast density compositions on thermal damage of breast tumor during radiofrequency ablation Applied Thermal Engineering 125 443-451

[12] Ewertowska E et al 2018 A clinically oriented computer model for radiofrequency ablation of hepatic tissue with internally cooled wet electrode International Journal of Hyperthermia 35 194-204 
[13] Zorbas G and Samaras T 2014 Simulation of radiofrequency ablation in real human anatomy International Journal of Hyperthermia 30 570-578

[14] Barauskas R, Gulbinas A, Vanagas T and Barauskas G 2008 Finite element modeling of cooled-tip probe radiofrequency ablation processes in liver tissue Computers in Biology and Medicine 38 694-708

[15] Singh S and Repaka R 2018 Parametric sensitivity analysis of critical factors affecting the thermal damage during RFA of breast tumor International Journal of Thermal Sciences 124 $366-374$

[16] Ooi E H et al 2019 The effects of electrical and thermal boundary condition on the simulation of radiofrequency ablation of liver cancer for tumours located near to the liver boundary Computers in Biology and Medicine 106 12-23

[17] Xu Y, Moser M A, Zhang E, Zhang W and Zhang B 2019 Large and round ablation zones with microwave ablation: A preliminary study of an optimal aperiodic tri-slot coaxial antenna with the $\pi$-matching network section International Journal of Thermal Sciences 140 539-548

[18] Singh S, Repaka R and Al-Jumaily A 2019 Sensitivity analysis of critical parameters affecting the efficacy of microwave ablation using Taguchi method International Journal of $R F$ and Microwave Computer-Aided Engineering 29 e21581

[19] Yang D, Converse M C, Mahvi D M and Webster J G 2007 Measurement and analysis of tissue temperature during microwave liver ablation IEEE Transactions on Biomedical Engineering 54 150-155

[20] Deshazer G, Prakash P, Merck D and Haemmerich D 2017 Experimental measurement of microwave ablation heating pattern and comparison to computer simulations International Journal of Hyperthermia 33 74-82

[21] Singh S and Melnik R 2019 Radiofrequency ablation for treating chronic pain of bones: Effects of nerve locations Bioinformatics and Biomedical Engineering IWBBIO 2019 (Lecture Notes in Computer Science vol 11466) ed Rojas I et al (Springer, Cham) p 418-429

[22] Singh S and Melnik R 2019 Computational analysis of pulsed radiofrequency ablation in treating chronic pain International Conference on Computational Science ICCS 2019 (Lecture Notes in Computer Science vol 11539) ed Rodrigues J et al (Springer, Cham) p 436450

[23] Chen R, Lu F, Wu F, Xie L and Kong D 2018 An analytical solution for temperature distributions in hepatic radiofrequency ablation incorporating the heat-sink effect of large vessels Physics in Medicine and Biology 63235026

[24] Ziemlewicz T J, Wells S A, Lubner M A, Musat A I, Hinshaw J L, Cohn A R and Lee F T 2014 Microwave ablation of giant hepatic cavernous hemangiomas Cardiovascular and Interventional Radiology 37 1299-1305

[25] Moreland A J et al 2014 High-powered microwave ablation of t1a renal cell carcinoma: safety and initial clinical evaluation Journal of Endourology 28 1046-1052

[26] Ganguli S, Brennan D D, Faintuch S, Rayan M E and Goldberg S N 2008 Immediate renal tumor involution after radiofrequency thermal ablation Journal of Vascular and Interventional Radiology 19 412-418

[27] Merkle E M, Nour S G and Lewin J S 2005 MR imaging follow-up after percutaneous radiofrequency ablation of renal cell carcinoma: findings in 18 patients during first 6 months Radiology 235 1065-1071

[28] Lee J K, Siripongsakun S, Bahrami S, Raman S S, Sayre, J and Lu D S 2016 Microwave ablation of liver tumors: degree of tissue contraction as compared to RF ablation Abdominal Radiology 41 659-666

[29] Brace C L, Diaz T A, Hinshaw J L and Lee F T 2010 Tissue contraction caused by radiofrequency and microwave ablation: A laboratory study in liver and lung Journal of Vascular and Interventional Radiology 21 1280-1286

[30] Sommer C M et al 2013 Quantification of tissue shrinkage and dehydration caused by microwave ablation: experimental study in kidneys for the estimation of effective coagulation volume Journal of Vascular and Interventional Radiology 24(8) 1241-1248

[31] Lopresto V et al 2018 CT-based investigation of the contraction of ex vivo tissue undergoing microwave thermal ablation Physics in Medicine \& Biology 63(5) 055019 
[32] Farina L, Nissenbaum Y, Cavagnaro M and Goldberg S N 2018 Tissue shrinkage in microwave thermal ablation: comparison of three commercial devices International Journal of Hyperthermia 34(4) 382-391

[33] Farina L et al 2014 Characterisation of tissue shrinkage during microwave thermal ablation International Journal of Hyperthermia 30(7) 419-428

[34] Amabile C et al 2017 Tissue shrinkage in microwave ablation of liver: an ex vivo predictive model International Journal of Hyperthermia 33(1) 101-109

[35] Rossmann C, Garrett-Mayer E, Rattay F and Haemmerich D 2013 Dynamics of tissue shrinkage during ablative temperature exposures Physiological Measurement 35(1) 55

[36] Liu D and Brace C L 2014 CT imaging during microwave ablation: analysis of spatial and temporal tissue contraction Medical Physics 41(11) 113303

[37] Keangin P, Wessapan T and Rattanadecho P 2011 Analysis of heat transfer in deformed liver cancer modeling treated using a microwave coaxial antenna Applied Thermal Engineering 31 3243-3254

[38] Keangin P and Rattanadecho P 2018 A numerical investigation of microwave ablation on porous liver tissue Advances in Mechanical Engineering 10 1-13

[39] Chaichanyut M and Tungjitkusolmun S 2016 Microwave ablation using four-tine antenna: effects of blood flow velocity, vessel location, and total displacement on porous hepatic cancer tissue Computational and Mathematical Methods in Medicine 20164846738

[40] Wongchadakul P, Rattanadecho P and Wessapan T 2018 Implementation of a thermomechanical model to simulate laser heating in shrinkage tissue (effects of wavelength, laser irradiation intensity, and irradiation beam area) International Journal of Thermal Sciences 134 321-336

[41] Li X, Zhong Y, Jazar R and Subic A 2014 Thermal-mechanical deformation modeling of soft tissues for thermal ablation Bio-Medical Materials and Engineering 24 2299-2310

[42] Li X, Zhong Y, Smith J and Gu C 2017 Non-Fourier based thermal-mechanical tissue damage prediction for thermal ablation Bioengineered $871-77$

[43] Karaki W, Lopez C A, Borca-Tasciuc D A and De S 2018 A continuum thermomechanical model of in vivo electrosurgical heating of hydrated soft biological tissues International Journal of Heat and Mass Transfer 127 961-974

[44] Liu D and Brace C L 2017 Numerical simulation of microwave ablation incorporating tissue contraction based on thermal dose Physics in Medicine and Biology 62 2070-2086

[45] Park C S, Hall S K, Liu C and Payne S J 2016 A model of tissue contraction during thermal ablation Physiological measurement 371474

[46] Park C S, Liu C, Hall S K and Payne S J 2018 A thermoelastic deformation model of tissue contraction during thermal ablation International Journal of Hyperthermia 34 221-228

[47] Shafirstein G and Feng Y 2013 Editorial: The role of mathematical modelling in thermal medicine International Journal of Hyperthermia 29 259-261

[48] Vedavarz A, Kumar S and Molallemi M K 1994 Non-Fourier heat waves in conduction Journal of Heat Transfer 117 221-223

[49] Kaminski W 1990 Hyperbolic heat conduction equation for materials with a nonhomogeneous inner structure ASME Journal of Heat Transfer 112 555-560

[50] Mitraa K, Kumar S, Vedavarz A and Moallemi M K 1995 Experimental evidence of hyperbolic heat conduction in processed meat ASME Journal of Heat Transfer 112 555-573

[51] Roetzel W, Putra N and Das S K 2005 Experiment and analysis for non-Fourier conduction in materials with a nonhomogeneous inner structure International Journal of Thermal Science 42 541-552

[52] Jaunich M, Raje S, Kim K, Mitra K and Guo Z 2008 Experimental and numerical analysis of short pulse laser interaction with tissue phantoms containing inhomogeneities International Journal of Heat and Mass Transfer 51 5511-5521

[53] Liu K C and Chen H T 2010 Investigation for the dual phase lag behaviour of bio-heat transfer International Journal of Thermal Science 49 1138-1146

[54] Sahoo N, Ghosh S, Narasimhan A and Das S K 2014 Investigation of non-Fourier effects in bio-tissues during laser assisted photothermal therapy International Journal of Thermal Sciences 76 208-220 
[55] Lu Y, Nan Q, Li L and Liu Y 2009 Numerical study on thermal field of microwave ablation with water-cooled antenna International Journal of Hyperthermia 25(2) 108-115

[56] González-Suárez A, Trujillo M, Burdío F, Andaluz A and Berjano E 2012 Feasibility study of an internally cooled bipolar applicator for RF coagulation of hepatic tissue: Experimental and computational study International Journal of Hyperthermia 28(7) 663-673

[57] Trujillo $M$ and Berjano E 2013 Review of the mathematical functions used to model the temperature dependence of electrical and thermal conductivities of biological tissue in radiofrequency ablation International Journal of Hyperthermia 29(6) 590-597

[58] Cavagnaro M, Pinto R and Lopresto V 2015 Numerical models to evaluate the temperature increase induced by ex vivo microwave thermal ablation Physics in Medicine \& Biology 60(8) 3287

[59] Deshazer G, Merck D, Hagmann M, Dupuy D E and Prakash P 2016 Physical modeling of microwave ablation zone clinical margin variance Medical Physics 43(4) 1764-1776

[60] Doss J D 1982 Calculation of electric fields in conductive media Medical Physics 9 566-573

[61] Pennes H H 1948 Analysis of tissue and arterial blood temperature in the resting human forearm Journal of Applied Physiology 193-122

[62] Abraham J P and Sparrow E M 2007 A thermal-ablation bioheat model including liquid-tovapor phase change, pressure-and necrosis-dependent perfusion, and moisture-dependent properties International Journal of Heat and Mass Transfer 50 2537-2544

[63] González-Suárez A, Pérez J J and Berjano E 2018 Should fluid dynamics be included in computer models of RF cardiac ablation by irrigated-tip electrodes? Biomedical Engineering Online 1743

[64] Cattaneo C 1958 A form of heat conduction equation which eliminates the paradox of instantaneous propagation Comptes Rendus 247 431-433

[65] Vernotte, P 1958 Les paradoxes de la theorie continue de l'equation de la chaleur Comptes Rendus 246 3154-3155

[66] Tzou D Y 1995 The generalized lagging response in small-scale and high-rate heating International Journal of Heat and Mass Transfer 38 3231-3240

[67] Maillet D 2019 A review of the models using the Cattaneo and Vernotte hyperbolic heat equation and their experimental validation International Journal of Thermal Sciences 139 424-432

[68] Strunin D V, Melnik R V N and Roberts A J 2001 Coupled thermomechanical waves in hyperbolic thermoelasticity Journal of Thermal Stresses 24 121-140

[69] O'Neill D P, Peng T, Stiegler P, Mayrhauser U, Koestenbauer S, Tscheliessnigg K and Payne S J 2011 A three-state mathematical model of hyperthermic cell death Annals of Biomedical Engineering 39 570-579

[70] Qadri A M, Chia N J Y and Ooi E H 2017 Effects of saline volume on lesion formation during saline-infused radiofrequency ablation Applied Mathematical Modelling 43 360-371

[71] Ji Z and Brace C L 2011 Expanded modeling of temperature-dependent dielectric properties for microwave thermal ablation Physics in Medicine and Biology 565249

[72] Lopresto V, Pinto R and Cavagnaro M 2014 Experimental characterisation of the thermal lesion induced by microwave ablation International Journal of Hyperthermia 30 110-118

[73] COMSOL Multiphysics ${ }^{\circledR}$ v. 5.2. www.comsol.com COMSOL AB Stockholm Sweden

[74] Wu T, Li P, Shao Q, Hong J, Yang L and Wu S 2013 A simulation-experiment method to characterize the heat transfer in ex-vivo porcine hepatic tissue with a realistic microwave ablation system Numerical Heat Transfer Part A: Applications 64 729-743

[75] Lopresto V, Argentieri A, Pinto R and Cavagnaro M 2019 Temperature dependence of thermal properties of ex vivo liver tissue up to ablative temperatures Physics in Medicine \& Biology 64(10) 105016 
Table 1. Magnitudes of thermal relaxation time for biological tissues.

\begin{tabular}{|c|c|c|}
\hline $\begin{array}{c}\tau_{\mathrm{q}} \\
{[\mathrm{s}]}\end{array}$ & $\begin{array}{c}\tau_{\mathrm{T}} \\
{[\mathrm{s}]}\end{array}$ & Reference \\
\hline $1-100$ & - & {$[48]$} \\
\hline $11-54$ & - & {$[49]$} \\
\hline 16 & 0.045 & {$[50]$} \\
\hline 1.77 & - & {$[51]$} \\
\hline $10-20$ & - & {$[52]$} \\
\hline $7.4-8.9$ & $14.5-21.4$ & {$[53]$} \\
\hline $2-8$ & 0.045 & {$[54]$} \\
\hline
\end{tabular}


Table 2. Thermo-electro-mechanical characterstics of different materials used in the present study.

\begin{tabular}{|c|c|c|}
\hline Parameter & Value & References \\
\hline \multicolumn{3}{|l|}{ Electrical model for MWA (@ 2.45 GHz) } \\
\hline Relative permittivity of tissue, $\varepsilon_{r \text {,tissue }}$ & Eq. (22) & {$[44]$} \\
\hline Electrical conductivity of tissue, $\sigma_{\text {tissue }}(\mathrm{S} / \mathrm{m})$ & Eq. (23) & {$[44]$} \\
\hline Relative permeability of tissue, $\mu_{r, \text { tissue }}$ & 1 & {$[37]$} \\
\hline Relative permittivity of dielectric, $\varepsilon_{r, \text { dielectric }}$ & 2.03 & {$[37]$} \\
\hline Electrical conductivity of dielectric, $\sigma_{\text {dielectric }}(\mathrm{S} / \mathrm{m})$ & 0 & {$[37]$} \\
\hline Relative permeability of dielectric, $\mu_{r \text {,dielectric }}$ & 1 & {$[37]$} \\
\hline Relative permittivity of catheter, $\varepsilon_{r, \text { catheter }}$ & 2.1 & [37] \\
\hline Electrical conductivity of catheter, $\sigma_{\text {catheter }}(\mathrm{S} / \mathrm{m})$ & 0 & {$[37]$} \\
\hline Relative permeability of catheter, $\mu_{r, \text { catheter }}$ & 1 & [37] \\
\hline Relative permittivity of slot, $\varepsilon_{r, s l o t}$ & 1 & {$[37]$} \\
\hline Electrical conductivity of slot, $\sigma_{\text {slot }}(\mathrm{S} / \mathrm{m})$ & 0 & {$[37]$} \\
\hline Relative permeability of slot, $\mu_{r, s l o t}$ & 1 & {$[37]$} \\
\hline \multicolumn{3}{|l|}{ Electrical model for RFA (@ $500 \mathbf{k H z}$ ) } \\
\hline Electrical conductivity of tissue, $\sigma_{\text {tissue }}(\mathrm{S} / \mathrm{m})$ & Eq. (24) & {$[16]$} \\
\hline Electrical conductivity of insulated part of RF electrode, $\sigma_{\text {plastic }}(\mathrm{S} / \mathrm{m})$ & $10^{-5}$ & [9] \\
\hline Electrical conductivity of active part of RF electrode, $\sigma_{\text {electrode }}(\mathrm{S} / \mathrm{m})$ & $7.4 \times 10^{6}$ & [9] \\
\hline \multicolumn{3}{|l|}{ Thermal model } \\
\hline Thermal conductivity of tissue, $k_{\text {tissue }}(\mathrm{W} / \mathrm{m} / \mathrm{K})$ & Eq. (25) & [16] \\
\hline Density of tissue before phase-change, $\rho_{l}\left(\mathrm{~kg} / \mathrm{m}^{3}\right)$ & 1080 & [63] \\
\hline Density of tissue post-phase-change, $\rho_{g}\left(\mathrm{~kg} / \mathrm{m}^{3}\right)$ & 370 & [63] \\
\hline Specific heat of tissue before phase-change, $c_{l}(\mathrm{~J} / \mathrm{kg} / \mathrm{K})$ & 3455 & {$[63]$} \\
\hline Specific heat of tissue post-phase-change, $c_{g}(\mathrm{~J} / \mathrm{kg} / \mathrm{K})$ & 2156 & [63] \\
\hline Latent heat of tissue, $H_{f g}\left(\mathrm{~J} / \mathrm{m}^{3}\right)$ & $2.162 \times 10^{9}$ & [63] \\
\hline Tissue water content, $C$ & 0.75 & {$[63]$} \\
\hline Thermal conductivity of active part of RF electrode, $k_{\text {electrode }}(\mathrm{W} / \mathrm{m} / \mathrm{K})$ & 15 & [9] \\
\hline Density of active part of RF electrode, $\rho_{\text {electrode }}\left(\mathrm{kg} / \mathrm{m}^{3}\right)$ & 8000 & [9] \\
\hline Specific heat of active part of RF electrode, $c_{\text {electrode }}(\mathrm{J} / \mathrm{kg} / \mathrm{K})$ & 480 & [9] \\
\hline
\end{tabular}




\begin{tabular}{|c|c|c|}
\hline Thermal conductivity of insulated part of RF electrode, $k_{\text {plastic }}(\mathrm{W} / \mathrm{m} / \mathrm{K})$ & 0.026 & [9] \\
\hline Density of insulated part of RF electrode, $\rho_{\text {plastic }}\left(\mathrm{kg} / \mathrm{m}^{3}\right)$ & 70 & [9] \\
\hline Specific heat of insulated part of RF electrode, $c_{\text {plastic }}(\mathrm{J} / \mathrm{kg} / \mathrm{K})$ & 1045 & [9] \\
\hline Metabolic heat generation, $Q_{m}\left(\mathrm{~W} / \mathrm{m}^{3}\right)$ & 33800 & [37] \\
\hline Blood perfusion rate $\left(\mathrm{s}^{-1}\right)$ & Eq. (26) & [50] \\
\hline Density of blood, $\rho_{\text {blood }}\left(\mathrm{kg} / \mathrm{m}^{3}\right)$ & 1060 & [37] \\
\hline Specific heat of blood, $c_{\text {blood }}(\mathrm{J} / \mathrm{kg} / \mathrm{K})$ & 3600 & [37] \\
\hline Blood (or reference) temperature, $T_{b}$ or $T_{r e f}\left({ }^{\circ} \mathrm{C}\right)$ & 37 & {$[9,37]$} \\
\hline \multicolumn{3}{|l|}{ Mechanical model } \\
\hline Thermal expansion coefficient, $\alpha\left(\mathrm{K}^{-1}\right)$ & $1 \times 10^{-4}$ & [37] \\
\hline Young's modulus, $E(\mathrm{~Pa})$ & $10.2 \times 10^{6}$ & [37] \\
\hline Poisson's ratio, $v$ & 0.48 & [37] \\
\hline \multicolumn{3}{|l|}{ Thermal damage model } \\
\hline Frequency factor, $A_{1}\left(\mathrm{~s}^{-1}\right)$ & $3.68 \times 10^{30}$ & [45] \\
\hline Frequency factor, $A_{2}\left(\mathrm{~s}^{-1}\right)$ & $5.68 \times 10^{3}$ & [45] \\
\hline Frequency factor, $A_{3}\left(\mathrm{~s}^{-1}\right)$ & $2.58 \times 10^{5}$ & [45] \\
\hline Activation energy, $\Delta E_{1}(\mathrm{~J} / \mathrm{mol})$ & $210 \times 10^{3}$ & [45] \\
\hline Activation energy, $\Delta E_{2}(\mathrm{~J} / \mathrm{mol})$ & $38.6 \times 10^{3}$ & [45] \\
\hline Activation energy, $\Delta E_{3}(\mathrm{~J} / \mathrm{mol})$ & $47.2 \times 10^{3}$ & [45] \\
\hline$L_{U} / L_{N}$ & 0.420 & [45] \\
\hline$L_{D} / L_{N}$ & 0.322 & [45] \\
\hline
\end{tabular}




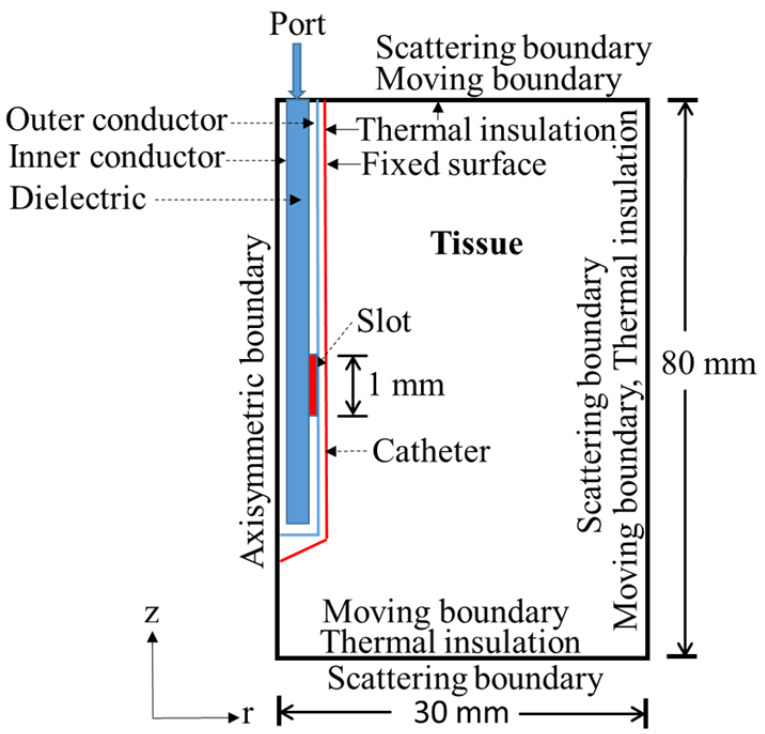

(a)

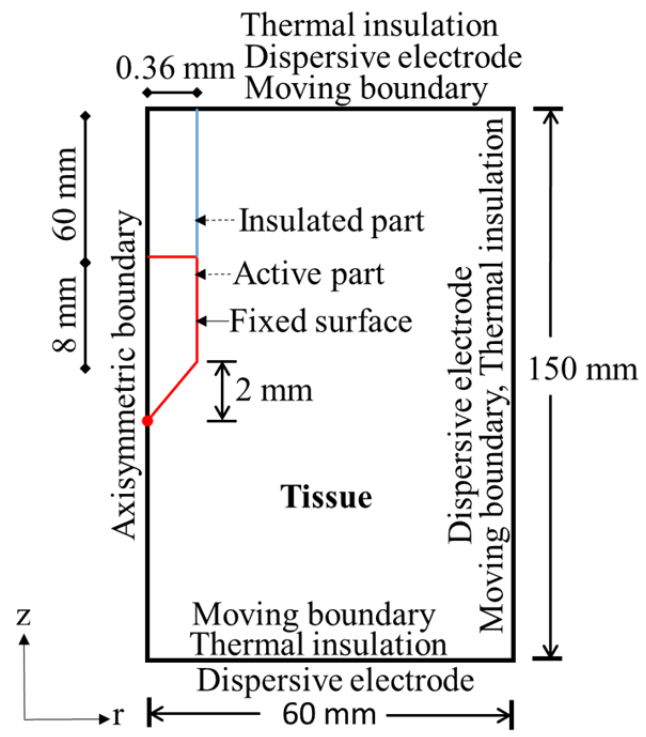

(b)

Figure 1: Schematic of two-dimensional axisymmetric model of thermal ablation considered in the present study: (a) MWA and (b) RFA (not to scale). 


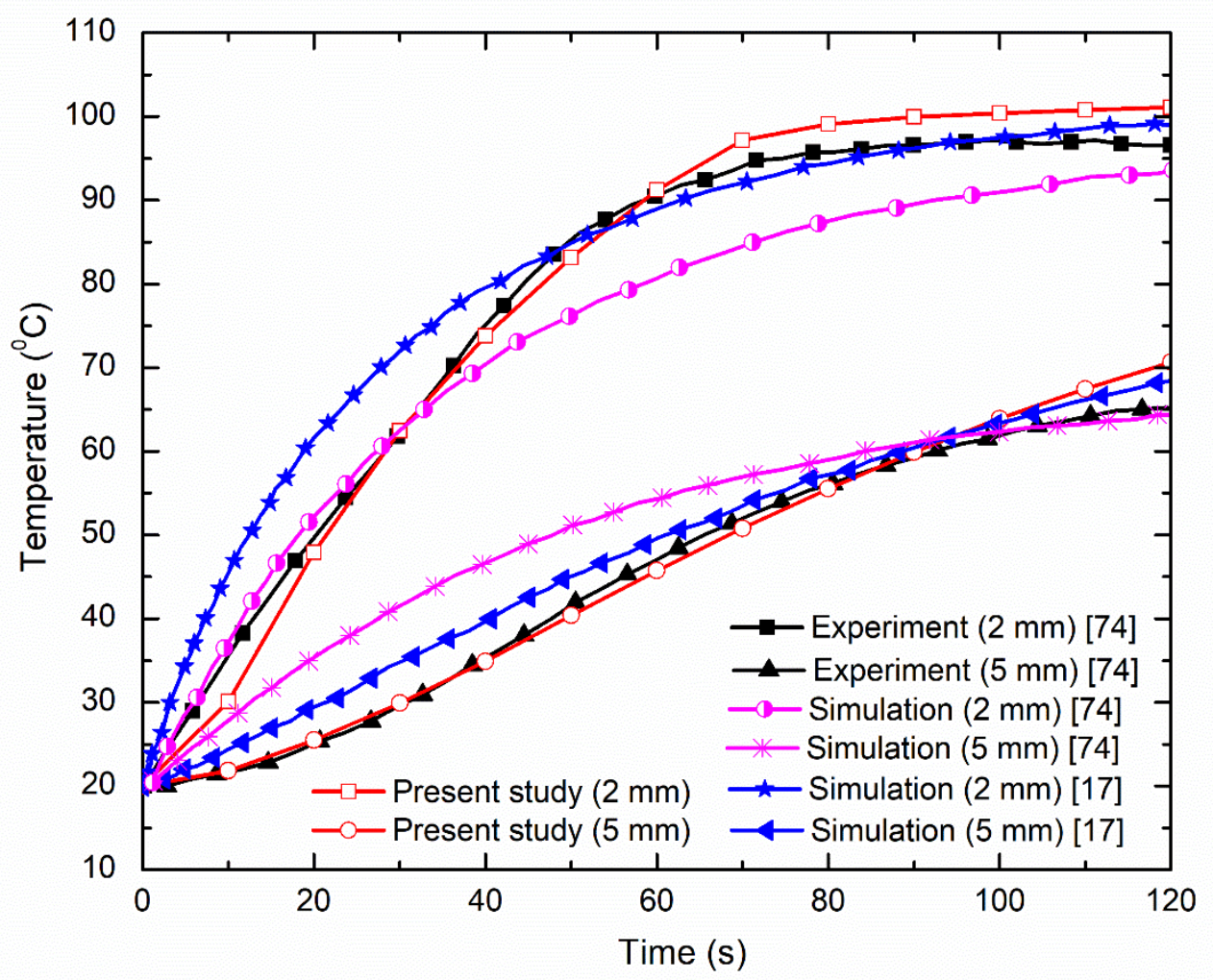

Figure 2: Comparison of the temperature profiles of the developed model against the experimental ex vivo study on liver tissue by Wu et al. [74]. 


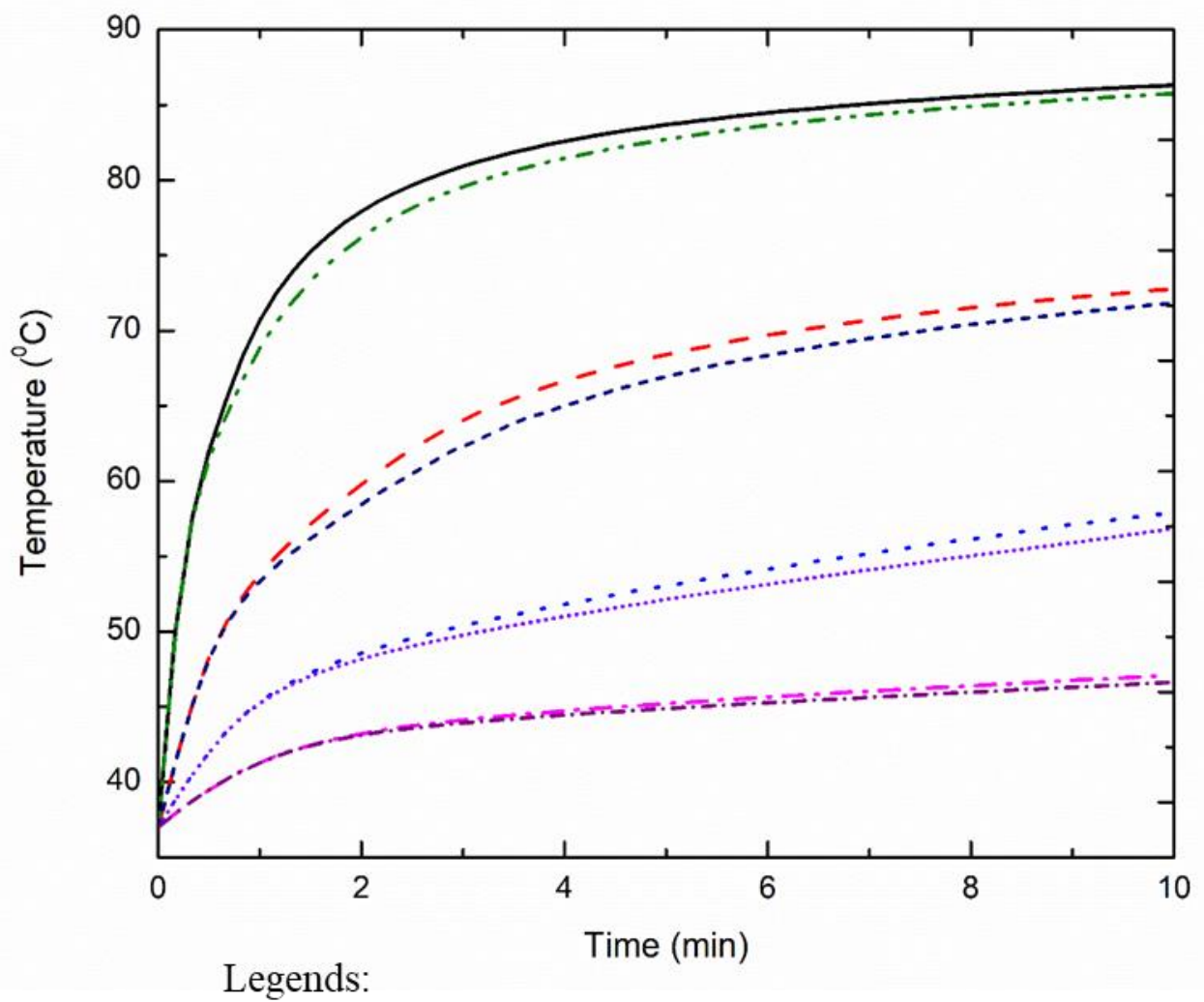

Legends:

- Model with mechanical coupling $(2.5 \mathrm{~mm})$

-.- Model without mechanical coupling $(2.5 \mathrm{~mm})$

- - Model with mechanical coupling $(5 \mathrm{~mm})$

-.--Model without mechanical coupling $(5 \mathrm{~mm})$

-... Model with mechanical coupling $(7.5 \mathrm{~mm})$

Model without mechanical coupling $(7.5 \mathrm{~mm})$

-. - Model with mechanical coupling $(10 \mathrm{~mm})$

-.--- Model without mechanical coupling $(10 \mathrm{~mm})$

Figure 3: Comparison of the temperature profiles relative to time at a position of 2.5, 5, 7.5 and $10 \mathrm{~mm}$ radially away from the slot center for the model with and without mechanical coupling during $20 \mathrm{~W}$ MWA procedure. 


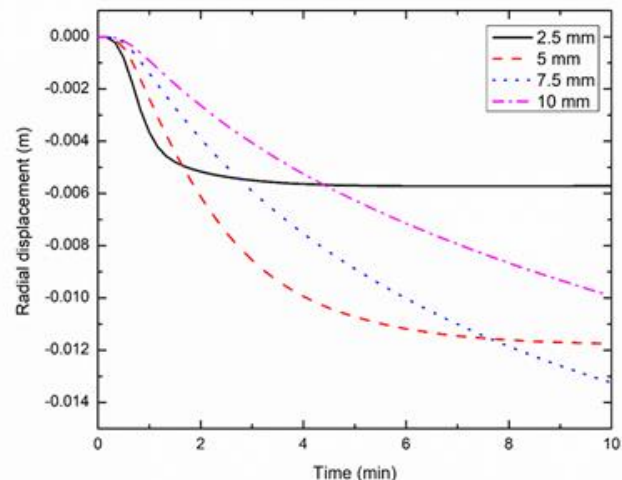

(a)

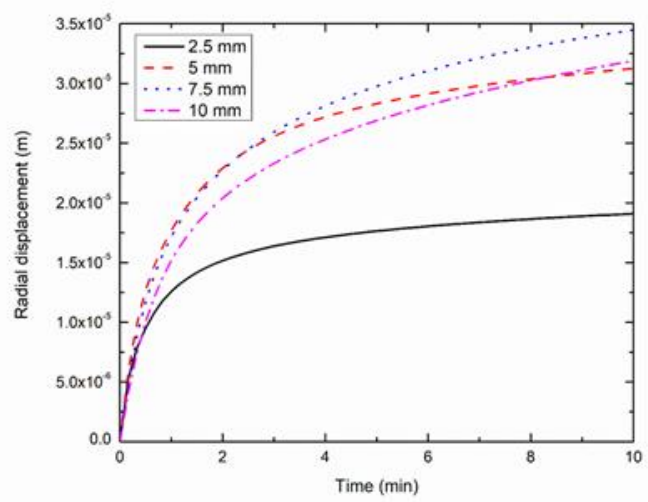

(c)

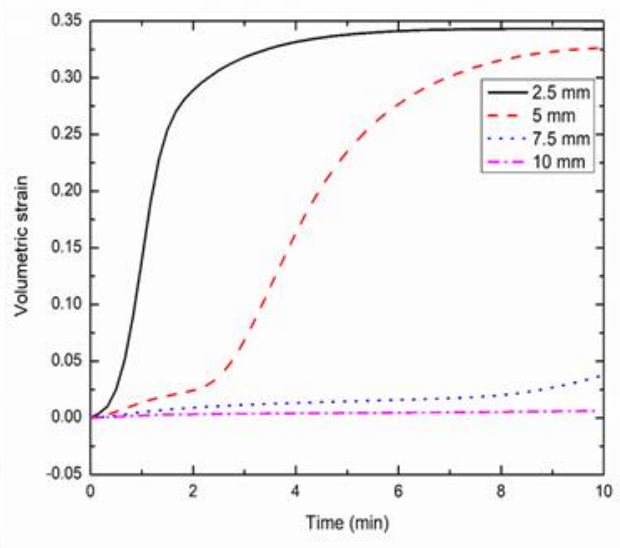

(e)

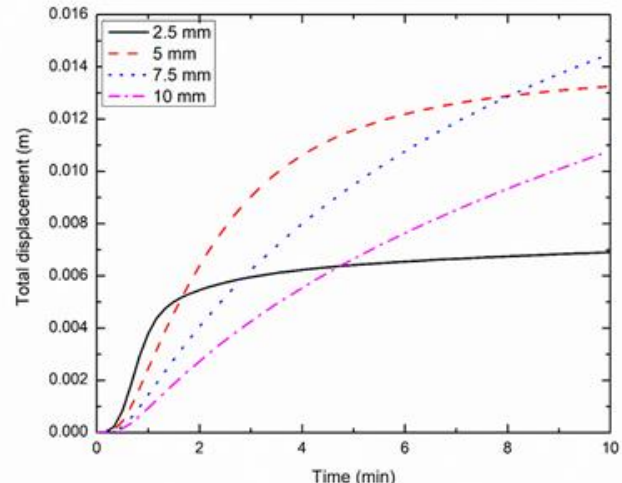

(b)

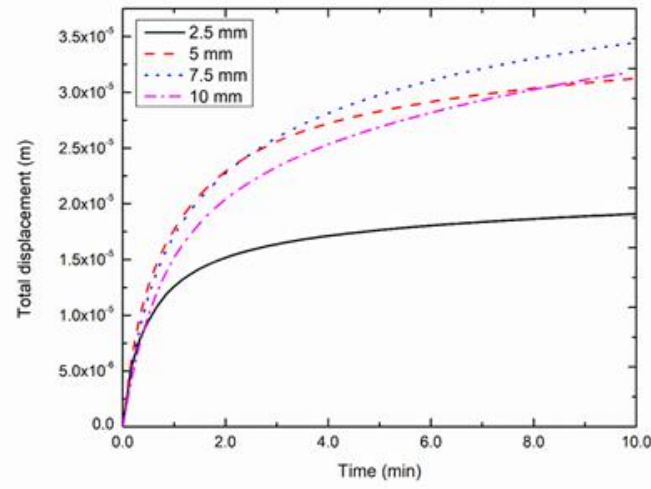

(d)

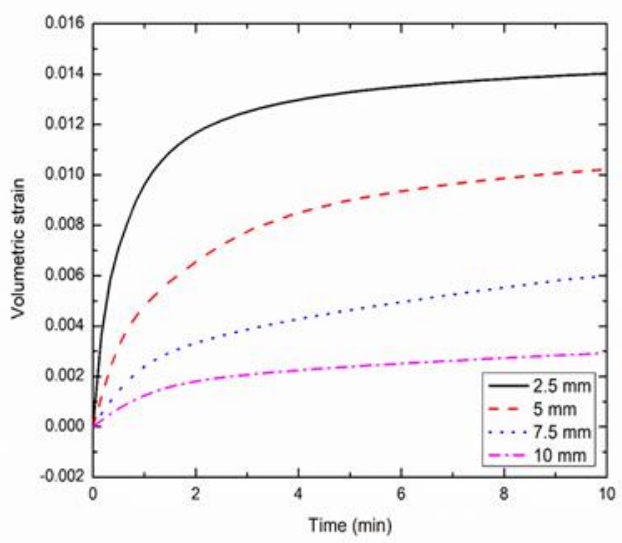

(f)

Figure 4: Time course of tissue radial displacement (a, c), total displacement (b, d), and volumetric strain for the coupled thermo-electro-mechanical model with and without thermal contraction caused by protein denaturation during $20 \mathrm{~W}$ MWA procedure. (a) and (b) present the displacements and (e) presents the volumetric strain for the model with tissue shrinkage, while (c) and (d) present the displacements and (f) presents the volumetric strain for the model without tissue shrinkage. 


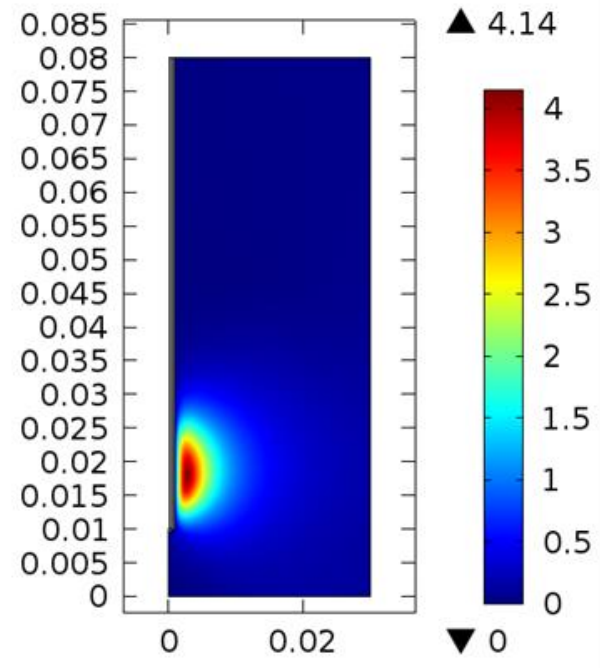

(a)

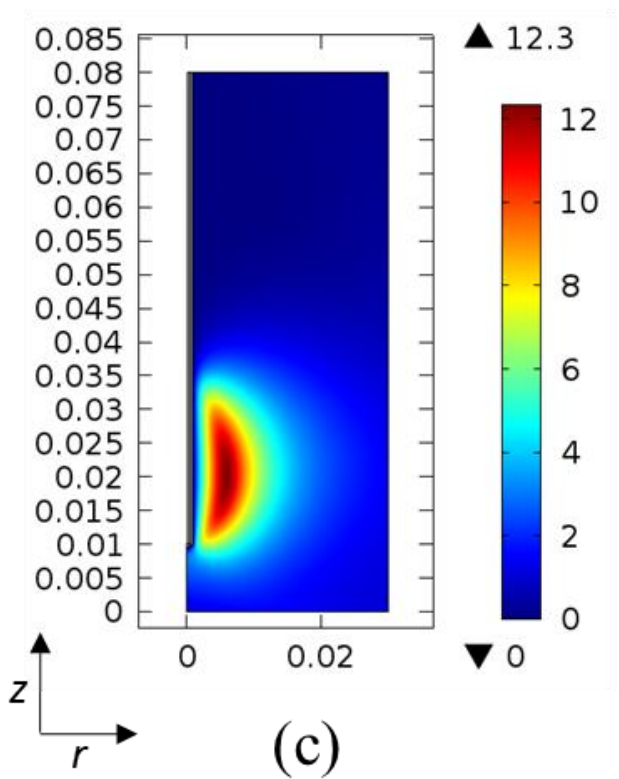

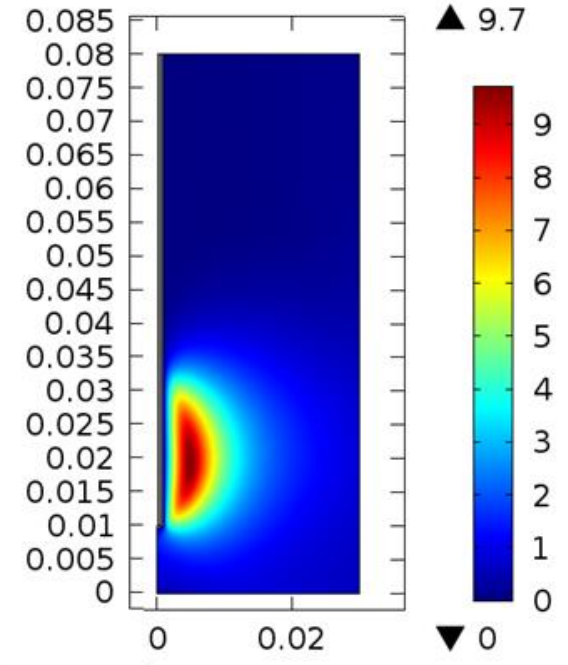

(b)

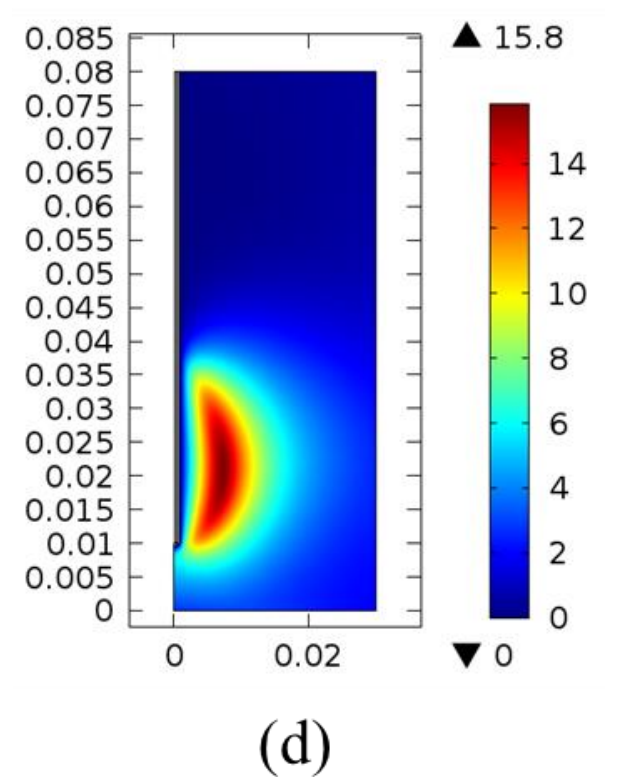

Figure 5: Total displacement distribution (in $\mathrm{mm}$ ) within the tissue towards the microwave antenna for the coupled thermo-electro-mechanical model subjected to $20 \mathrm{~W}$ MWA at different times: (a) $1 \mathrm{~min}$; (b) $3 \mathrm{~min}$; (c) $5 \mathrm{~min}$; and (d) $10 \mathrm{~min}$ (The geometric axes are displayed in " $\mathrm{m}$ " with a $5 \mathrm{~mm}$ slot centered at $z=0.016 \mathrm{~m}$ ). 


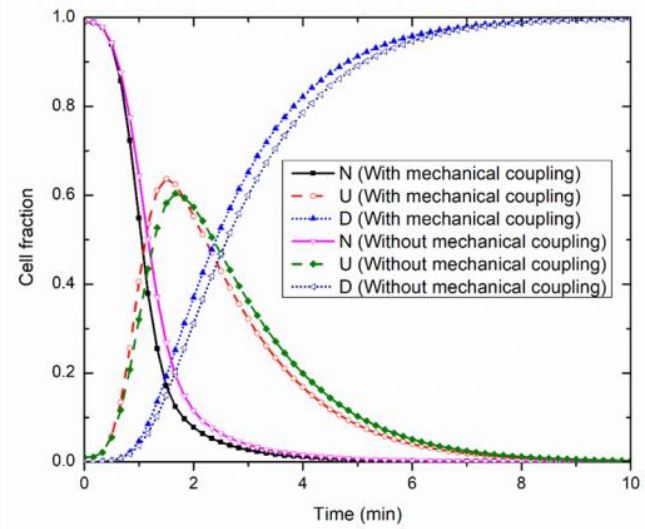

(a)

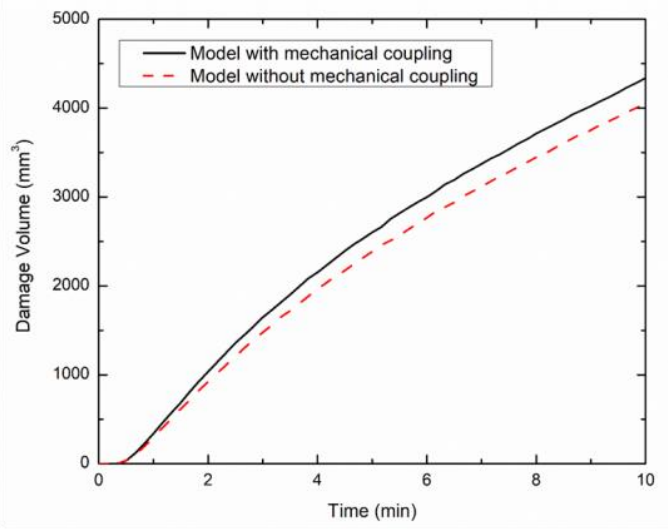

(b)

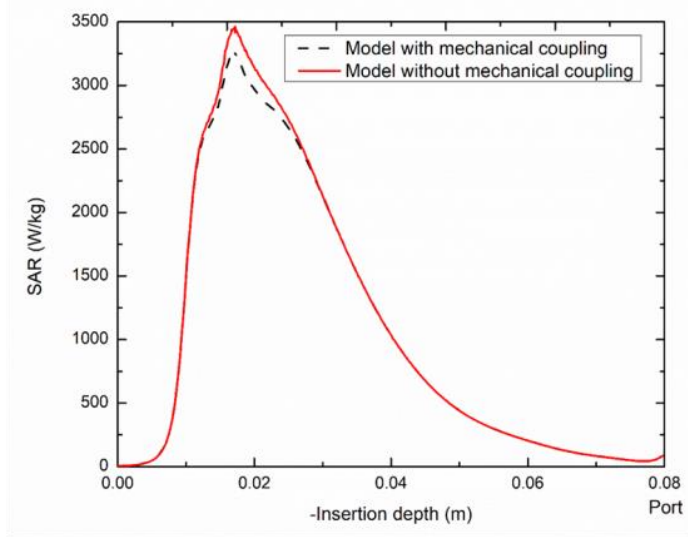

(c)

Figure 6: Variation of time course of: (a) fractions of cells in native $(N)$, unfolded $(U)$ and denatured $(D)$ states at a position of $2.5 \mathrm{~mm}$ radially away from the slot center, (b) damage volume, for the model with and without mechanical coupling, and (c) comparison of SAR distribution along the insertion depth of MW antenna for the model with and without mechanical coupling during $20 \mathrm{~W}$ MWA. 


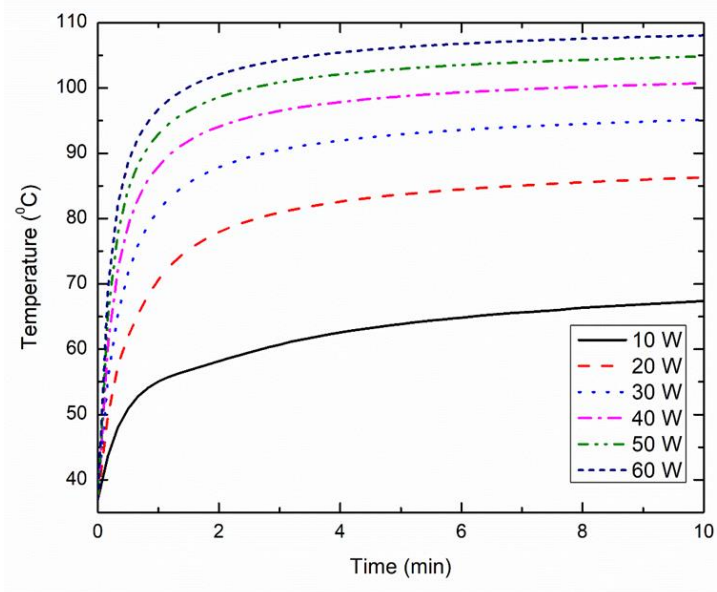

(a)

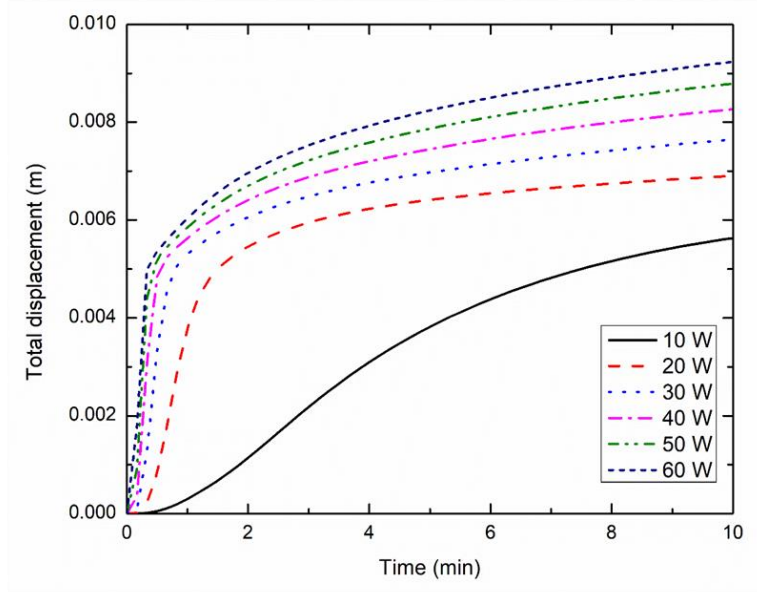

(b)

Figure 7: The effect of input MW power on (a) the temperature distribution, and (b) the total displacement of tissue at the position of $2.5 \mathrm{~mm}$ radially away from the slot center. 


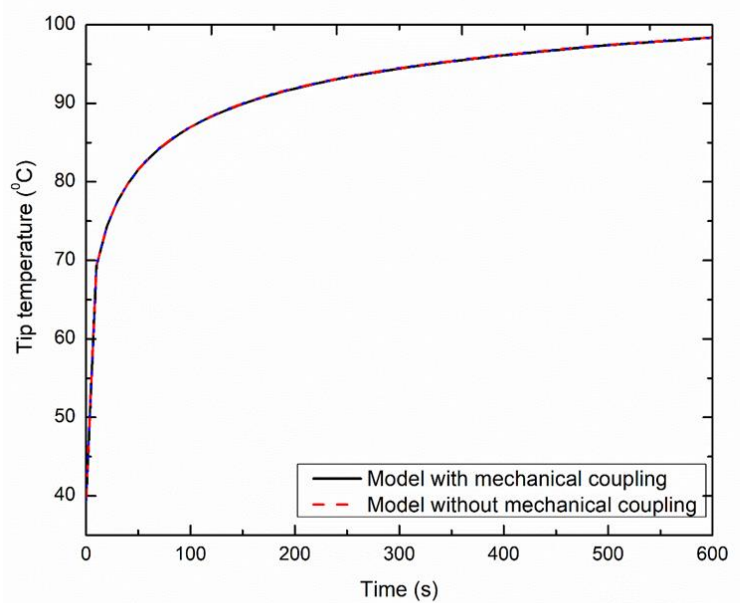

(a)

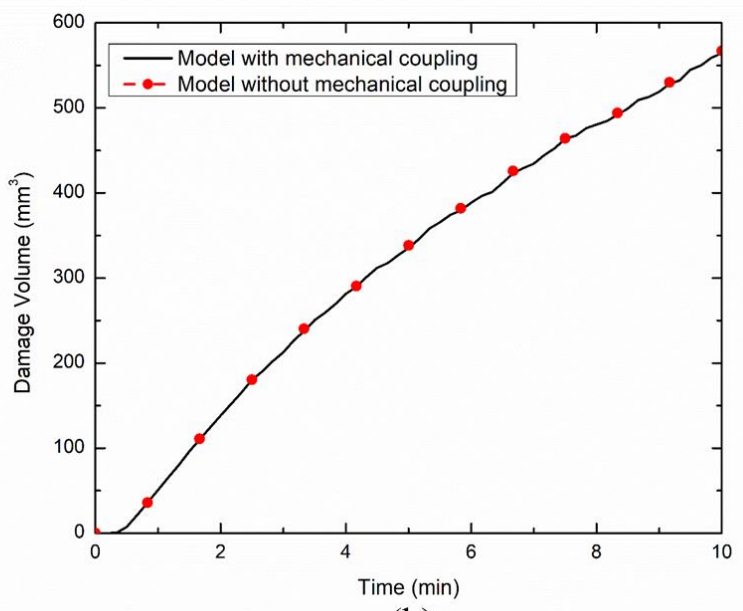

(b)

Figure 8: The effect of mechanical coupling on (a) the tip temperature, and (b) the damage volume during $20 \mathrm{~V}$ RFA. 


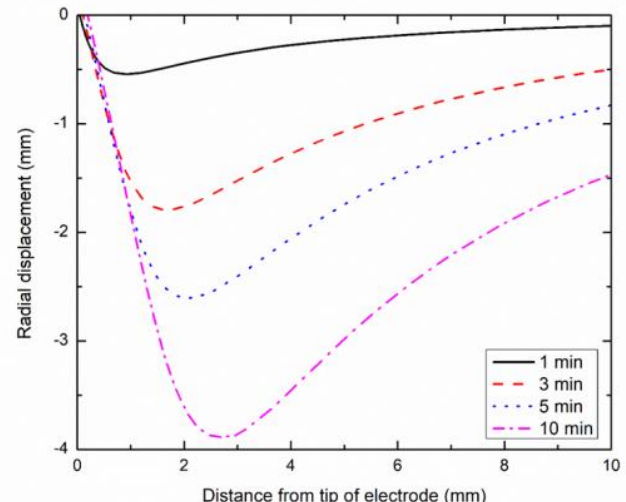

(a)

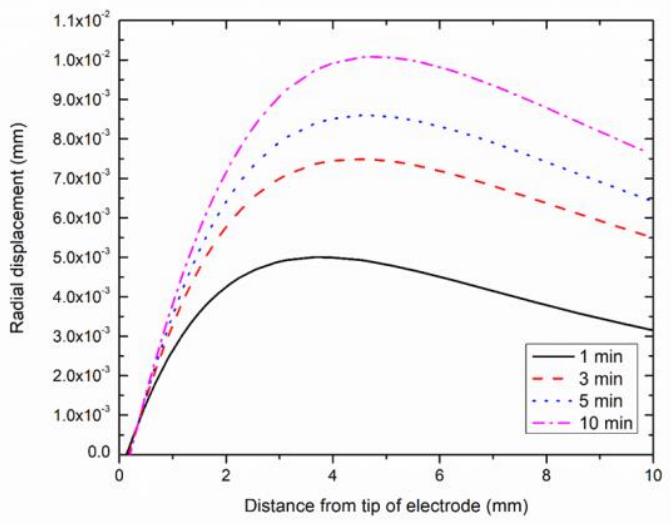

(c)

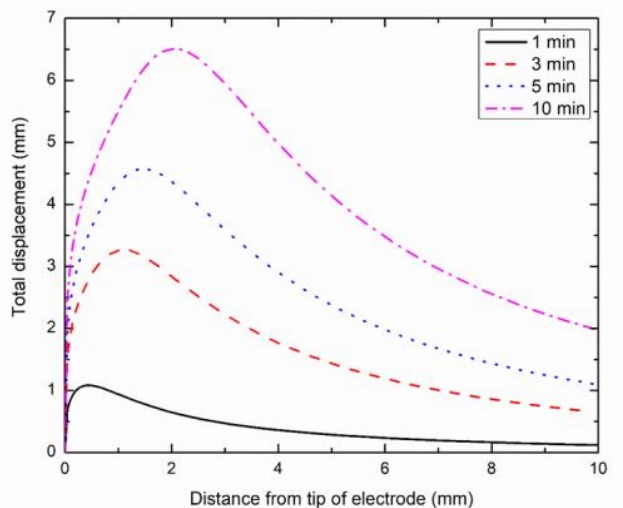

(b)

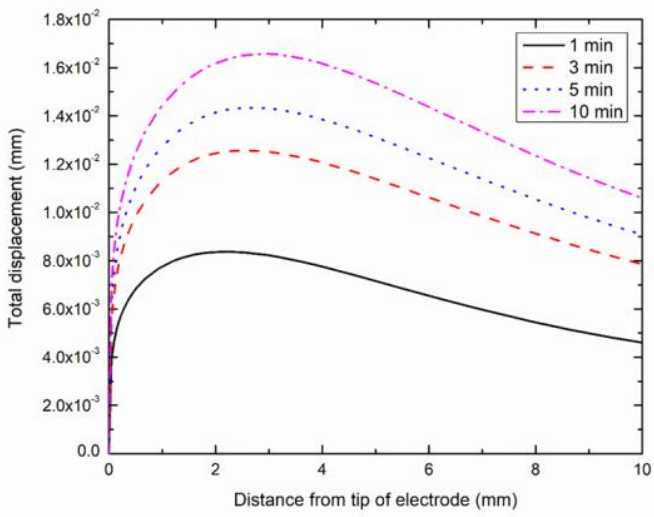

(d)

Figure 9: Variation of the tissue radial $(a, c)$ and total displacement $(b, d)$ as a function of distance (measured perpendicularly) from the tip of RF electrode for the coupled thermoelectro-mechanical model during $20 \mathrm{~V}$ RFA. (a) and (b) present the displacements for the model with tissue shrinkage, while (c) and (d) present the displacements for the model without tissue shrinkage. 


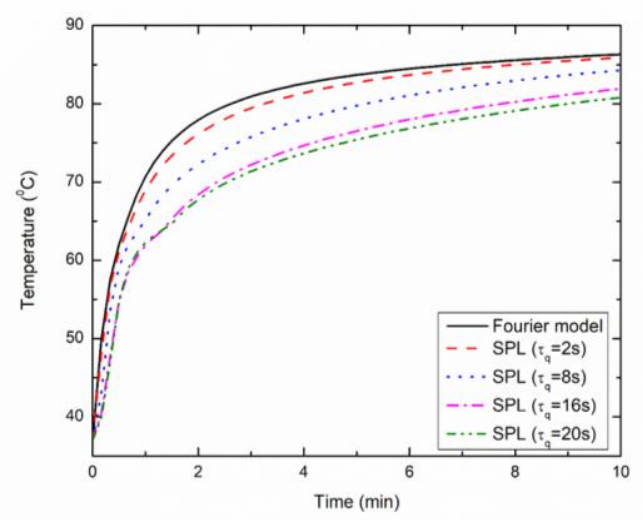

(a)

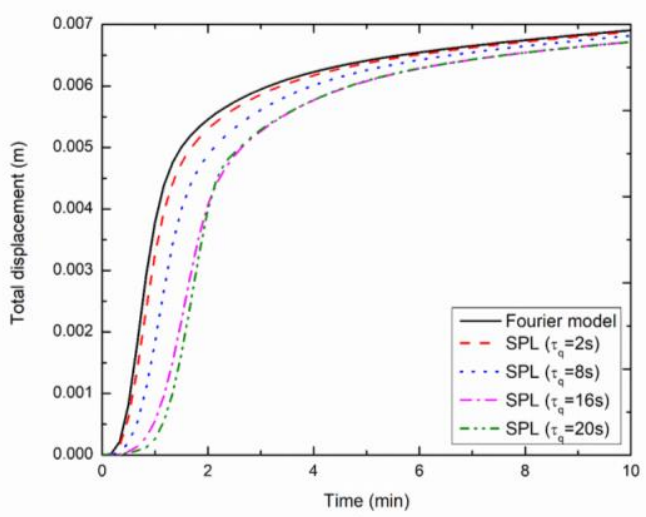

(b)

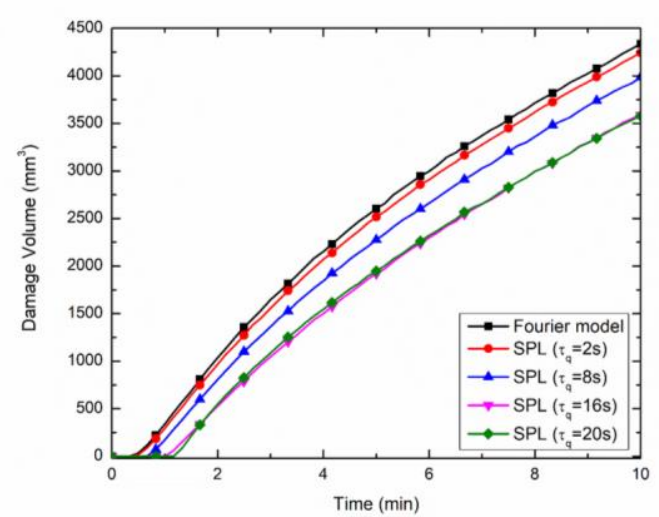

(c)

Figure 10: The effect of single-phase-lag (SPL) model on (a) temperature distribution, (b) total displacement of tissue, and (c) damage volume during 20 W MWA. 

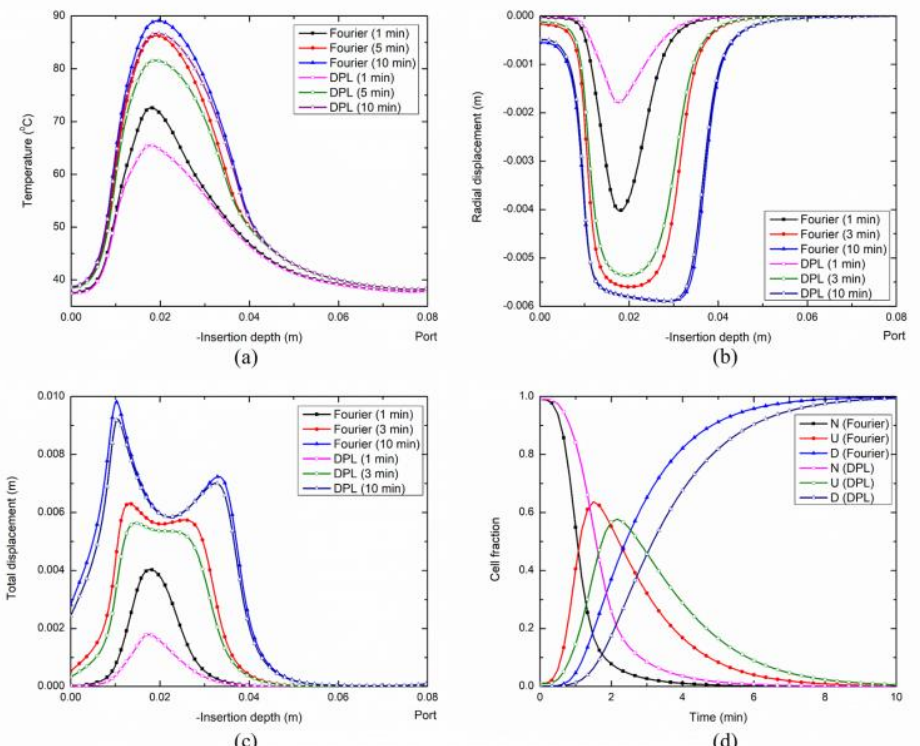

(c)

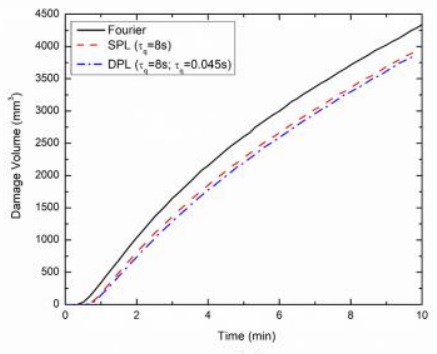

Figure 11: The effect of dual-phase-lag (DPL) model during $20 \mathrm{~W}$ MWA on (a) temperature distribution, (b) radial displacement, (c) total displacement, (d) fractions of cells in native $(N)$, unfolded $(U)$ and denatured $(D)$ states, and (e) damage volume. 


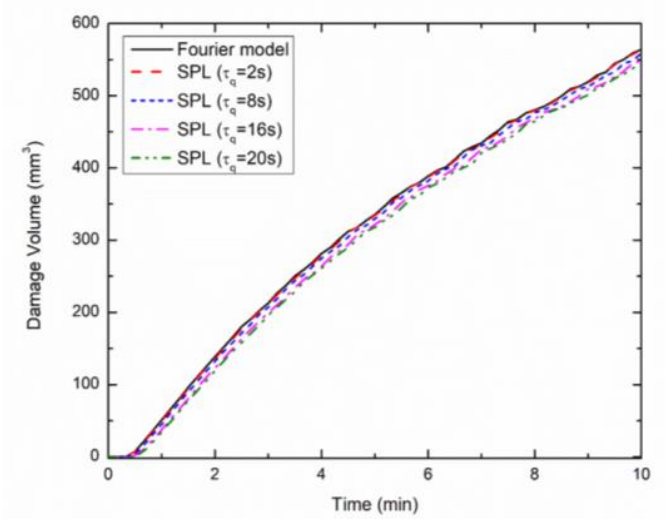

(a)

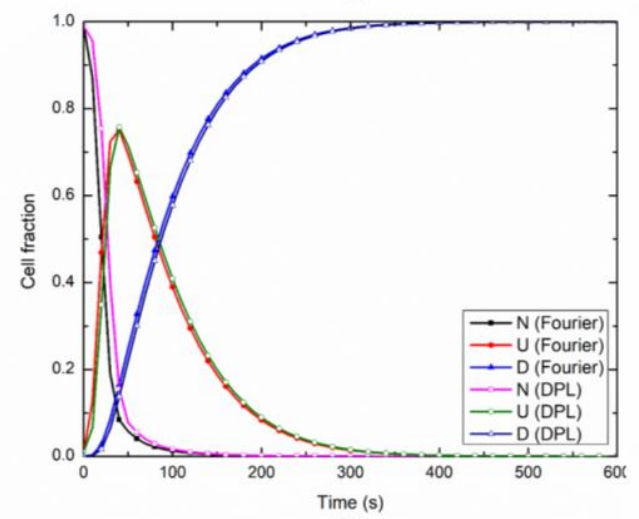

(c)

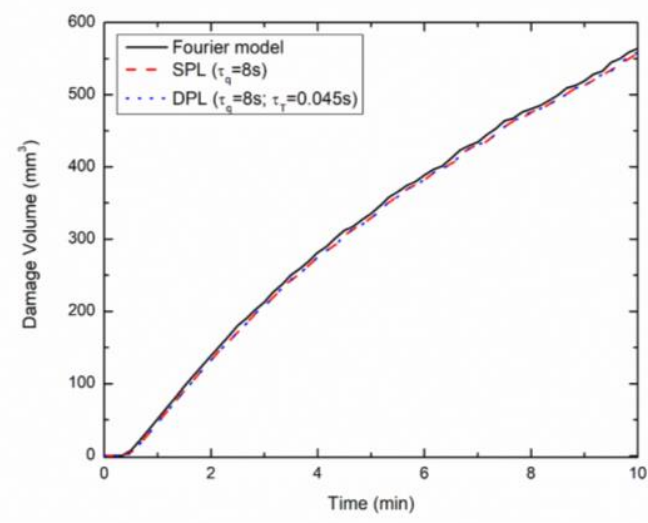

(b)

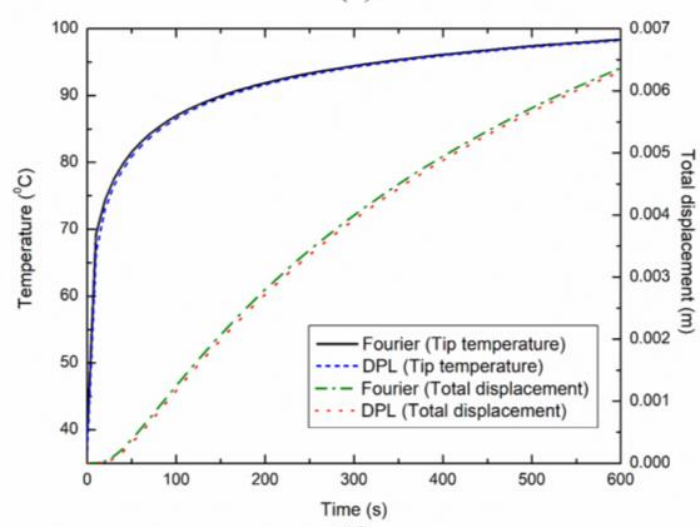

(d)

Figure 12: The effect of non-Fourier heat transfer on the coupled thermo-electro-mechanical model subjected to $20 \mathrm{~V}$ RFA. Temporal variation of: (a) damage volume with single-phaselag (SPL) model, (b) damage volume with dual-phase-lag (DPL) model, (c) fractions of cells in native $(N)$, unfolded $(U)$ and denatured $(D)$ states, and (d) temperature and total displacement in the biological tissue due to thermal strain. 


\section{Table Captions}

Table 1. Magnitudes of thermal relaxation time for biological tissues.

Table 2. Thermo-electro-mechanical characterstics of different materials used in the present study. 


\section{Figure Captions}

Figure 1: Schematic of two-dimensional axisymmetric model of thermal ablation considered in the present study: (a) MWA and (b) RFA (not to scale).

Figure 2: Comparison of the temperature profiles of the developed model against the experimental ex vivo study on liver tissue by Wu et al. [74].

Figure 3: Comparison of the temperature profiles relative to time at a position of $2.5,5,7.5$ and $10 \mathrm{~mm}$ radially away from the slot center for the model with and without mechanical coupling during $20 \mathrm{~W}$ MWA procedure.

Figure 4: Time course of tissue radial displacement (a, c), total displacement (b, d), and volumetric strain for the coupled thermo-electro-mechanical model with and without thermal contraction caused by protein denaturation during $20 \mathrm{~W}$ MWA procedure. (a) and (b) present the displacements and (e) presents the volumetric strain for the model with tissue shrinkage, while (c) and (d) present the displacements and (f) presents the volumetric strain for the model without tissue shrinkage.

Figure 5: Total displacement distribution (in $\mathrm{mm}$ ) within the tissue towards the microwave antenna for the coupled thermo-electro-mechanical model subjected to $20 \mathrm{~W}$ MWA at different times: (a) $1 \mathrm{~min}$; (b) $3 \mathrm{~min}$; (c) $5 \mathrm{~min}$; and (d) $10 \mathrm{~min}$ (The geometric axes are displayed in " $\mathrm{m}$ " with a $5 \mathrm{~mm}$ slot centered at $z=0.016 \mathrm{~m}$ ).

Figure 6: Variation of time course of: (a) fractions of cells in native $(N)$, unfolded $(U)$ and denatured $(D)$ states at a position of $2.5 \mathrm{~mm}$ radially away from the slot center, (b) damage volume, for the model with and without mechanical coupling, and (c) comparison of SAR distribution along the insertion depth of MW antenna for the model with and without mechanical coupling during $20 \mathrm{~W}$ MWA.

Figure 7: The effect of input MW power on (a) the temperature distribution, and (b) the total displacement of tissue at the position of $2.5 \mathrm{~mm}$ radially away from the slot center.

Figure 8: The effect of mechanical coupling on (a) the tip temperature, and (b) the damage volume during $20 \mathrm{~V}$ RFA.

Figure 9: Variation of the tissue radial $(a, c)$ and total displacement $(b, d)$ as a function of distance (measured perpendicularly) from the tip of RF electrode for the coupled thermoelectro-mechanical model during $20 \mathrm{~V}$ RFA. (a) and (b) present the displacements for the model with tissue shrinkage, while (c) and (d) present the displacements for the model without tissue shrinkage.

Figure 10: The effect of single-phase-lag (SPL) model on (a) temperature distribution, (b) total displacement of tissue, and (c) damage volume during $20 \mathrm{~W}$ MWA.

Figure 11: The effect of dual-phase-lag (DPL) model during $20 \mathrm{~W}$ MWA on (a) temperature distribution, (b) radial displacement, (c) total displacement, (d) fractions of cells in native $(N)$, unfolded $(U)$ and denatured $(D)$ states, and (e) damage volume. 
Figure 12: The effect of non-Fourier heat transfer on the coupled thermo-electro-mechanical model subjected to $20 \mathrm{~V}$ RFA. Temporal variation of: (a) damage volume with single-phaselag (SPL) model, (b) damage volume with dual-phase-lag (DPL) model, (c) fractions of cells in native $(N)$, unfolded $(U)$ and denatured $(D)$ states, and (d) temperature and total displacement in the biological tissue due to thermal strain. 